\title{
NUEVAS LUCES SOBRE UN ANTIGUO TESTIMONIO ACERCA DE LOS MAYAS: EL INFORME DE LA EXPEDICIÓN COMANDADA POR JUAN DE GRIJALVA
}

\author{
María del Carmen León Cázares \\ Centro de Estudios Mayas, Instituto de Investigaciones Filológicas, \\ Universidad Nacional Autónoma de México
}

\begin{abstract}
RESUMEN: El objetivo general de este estudio es destacar la necesidad de someter a la crítica ecdótica y al análisis historiográfico los textos que, a lo largo de su trabajo, el investigador aprovecha como fuentes de conocimiento histórico; su objetivo particular es presentar los avances logrados en este sentido respecto al primer testimonio impreso sobre la cultura maya antes de la Conquista. En busca de comprender la visión geográfica del autor de este informe, se analizan las ideas vigentes en el contexto de su redacción. Para explicar los problemas de su transmisión, se estudian las ediciones impresas en el siglo xvı. En cuanto a la cuestión de su autoría, se propone una distinta a la aceptada a partir de la edición mexicana del siglo XIX.

PAlabras Clave: historiografía, geografía, cartografía, exploración, imprenta.

ABSTRACT: In this research we pretend to highlight the importance of submitting historical texts, used as trustable sources of knowledge, under ecdotics review and historiographical analysis; its particular aim is to present the current advances achieved in the study of the first printed testimony of the Maya culture before the Conquest. In search of understanding the author's geographical point of view used in the report, the current ideas of the context of writing are analyzed. To explain the problems of transmission, sixteenth century printed editions were studied. As to the question of its authorship, we propose a different one to the accepted from the Mexican edition of the nineteenth century.
\end{abstract}

KEYwORDS: historiography, geography, cartography, exploration, printing.

RECEPCIÓN: 4 de septiembre de 2014.

ACEPTACIÓN: 13 de diciembre de 2014. 



\title{
NUEVAS LUCES SOBRE UN ANTIGUO TESTIMONIO ACERCA DE LOS MAYAS: EL INFORME DE LA EXPEDICIÓN COMANDADA POR JUAN DE GRIJALVA ${ }^{1}$
}

\author{
María del Carmen León Cázares \\ Centro de Estudios Mayas, Instituto de Investigaciones Filológicas, \\ Universidad Nacional Autónoma de México
}

Como tantos otros informes relacionados con el avance de las exploraciones realizadas por los europeos en ultramar, a Pedro Mártir de Anglería, humanista lombardo al servicio de los Reyes Católicos, se debe la primera noticia difundida por la imprenta acerca de la existencia de una región, situada hacia el poniente del litoral reconocido por Cristóbal Colón durante su cuarto viaje, llamada Ma'ia. Un nombre que habían escuchado los expedicionarios de boca de ciertos mercaderes indígenas que transportaban productos desde aquel territorio, en dos grandes canoas por la costa de Honduras, y que había de divulgarse a partir de noviembre de 1516, cuando se publicó en Alcalá de Henares el libro De orbe nouo decades, meses antes del descubrimiento de la supuesta isla bautizada como Yucatán. ${ }^{2}$ Sin embargo, fue a partir de 1520 cuando la imprenta empezó a divulgar el primer testimonio sobre las características y los alcances de la civilización que los pueblos, hoy reconocidos como integrantes de la cultura maya, habían logrado crear.

A don Joaquín García Icazbalceta corresponde el mérito de haber rescatado este relato para la historiografía mexicana, cuando en 1858 lo publicó en español, por primera vez, junto con la versión impresa en una edición veneciana de 1522 , en el volumen inicial de su Colección de documentos para la historia de México. ${ }^{3}$ El erudito bibliófilo compuso su edición a partir de dos copias manuscritas del texto

\footnotetext{
${ }^{1}$ Agradezco al Dr. René Ceceña la lectura de este trabajo y sus pertinentes observaciones.

${ }^{2}$ Pietro Martire d'Anghiera, De orbe nouo decades. Alcalá [de Henares], Antonii Nebrissensis [ed.], 1516. Este ejemplar no tiene paginación, pero el nombre de ma'ia aparece en las figuras 98 y 111 de la versión digital. Libro disponible en la página electrónica Internet Archive. Para la versión en español véase Pedro Mártir de Anglería, Décadas del Nuevo Mundo, Edmundo O'Gorman (est. y ap.), Agustín Millares Carlo (trad. del latín), J. A. Sinclair (ap. bibl.), 2 v. México: José Porrúa e Hijos, 1964, "Década" III, lib. IV y VI, v. I, pp. 317-318, 343.

3 "Itinerario de la armada del rey católico á la isla de Yucatán...”, Colección de documentos..., v. I, pp. 281-308, Joaquín García Icazbalceta (ed.). México, 1858-1866. Las citas que aparecen en el presente trabajo corresponden a esta edición siempre que el título esté entre comillas.
} 
que localizó, obtuvo y tradujo. ${ }^{4}$ Entonces lo presentó bajo el encabezado con el cual aparecía en aquel impreso: "Itinerario de la armada del Rey Católico á la isla de Yucatán, en la India, el año 1518, en la que fue por comandante y capitán general Juan de Grijalva. Escrito para su alteza por el capellán mayor de la dicha armada", 5 título con el que se conoce hasta nuestros días y que lo clasifica entre los relatos escritos por viajeros, exploradores, conquistadores, misioneros, y todo tipo de trotamundos, durante o a raíz de una travesía marítima o terrestre.

Un testimonio que presenta interesantes problemas de transmisión, no sólo por el camino accidentado que ha recorrido desde que salió de la pluma de su autor hasta convertirse en fuente de conocimiento histórico para los investigadores actuales, sino también porque manifiesta la visión geográfica de quien lo escribió, en un momento en que una secular imagen del mundo y sus zonas habitables se transformaba de manera radical y definitiva, gracias a las exploraciones oceánicas; circunstancias que vuelven necesario someterlo a los requerimientos del análisis historiográfico, pero también al examen de la geografía histórica. En este caso, la conjunción de ambas perspectivas permitirá profundizar en la comprensión del proceso histórico que resultó en la ocupación de estas tierras por los europeos y el sometimiento de estos pueblos a la Corona española.

\section{II}

Esta relación es un documento de carácter testimonial, que recoge las primeras impresiones recibidas por un expedicionario, convertido en escritor por las circuns-

\footnotetext{
${ }^{4}$ García Icazbalceta señala que una copia provenía de la colección de Juan Bautista Muñoz que Prescott le había enviado y la otra había sido hecha por Martín Fernández de Navarrete, tomada de un impreso en lengua toscana, fechado en Venecia el 17 de septiembre de 1522, el cual se conservaba en la Biblioteca Colombina de la Catedral de Sevilla. Además, consultó la traducción francesa editada por Ternaux-Compans, en el tomo X de su colección de Voyages, Relations et Mémoires... aparecida entre 1837 y 41. "Noticias de las piezas contenidas en este volumen. Itinerario de Grijalva”, ibid., pp. XIV-XV.

5 La traducción de García Icazbalceta, sin sus notas, ha sido reimpresa en 1939, 50, 63 y 87, en la antología Crónicas de la Conquista, preparada por Agustín Yáñez como vol. 2 de la Biblioteca del Estudiante Universitario de la UNAM; el 1 de enero de 1958 por Carlos R. Menéndez en el Diario de Yucatán y por Jorge Gurría. Este historiador, con base en los registros proporcionados por Henry Harrisse en su Bibliotheca Americana Vetustissima. Description of Works relating to America published between the years 1492 and 1551. New York: Geo. P. Philes, Publisher, 1866, y en Additions. Paris: Libraire Tross, 1872, publicó los facsímiles de cinco impresos del siglo xvı donde se da cuenta de las primeras exploraciones sobre las costas del territorio que se llamaría la Nueva España, seguidos de sus respectivas traducciones y precedidos con notas introductorias compuestas por el mismo editor, bajo el sello editorial de la Colección Juan Pablos, entre 1972 y 1973. El Itinerario es el número I y apareció con el título registrado por García Icazbalceta, el II corresponde al opúsculo Provincias y regiones recientemente descubiertas en las Indias Occidentales, en el último viaje, el III a la Carta enviada desde la isla de Cuba, de India, en la cual se habla de ciudades, gentes y animales encontrados nuevamente en el año de 1519 por los españoles; el IV reproduce el Epítome de Pedro Mártir de las islas recientemente descubiertas bajo el reino de don Carlos y de las costumbres de sus habitantes. Dedicado a Doña Margarita, hija del ínclito Emperador Maximiliano; en el quinto y último apareció la Nueva noticia del país que los españoles encontraron en el año de 1521, llamado Yucatán, impreso alemán de 1522, al parecer basado en el Epítome.
} 
tancias, al contemplar tierras apenas encontradas y hombres nunca antes vistos. Es una descripción donde necesariamente se señalan rutas náuticas, se esboza el escenario geográfico y se da cuenta de las características físicas y hasta de algunos rasgos culturales observables en los pobladores de aquel territorio todavía incógnito.

Además de los conocimientos que aporta sobre la exploración de los mares y costas descubiertos a partir de la navegación desde las Antillas, y como antecedente inmediato de la expedición comandada por Hernán Cortés, considero este documento como uno de los primeros testimonios y el más significativo en el inicio de la formación de la imagen historiográfica de los pueblos asimilados en la actualidad como integrantes de la cultura maya, representados aquí por los peninsulares, los chontales y, desde el punto de vista lingüístico, por los huastecos, en razón de los juicios del autor acerca de su carácter. Apreciaciones cuya difusión impresa contribuyó a volverlas perdurables. Sin soslayar que también es el primero donde se encuentran datos sobre otros habitantes de la costa del Golfo, en especial totonacas y nahuas, además de ofrecer la noticia inaugural acerca de la existencia del Imperio tenochca, su riqueza y poderío.

Recordemos que se trata de una de las relaciones escritas durante el viaje de exploración e intercambio comercial organizado por Diego Velázquez, teniente de gobernador en Cuba, comandado por Juan de Grijalva y conducido por el piloto Antón de Alaminos, en 1518, con el fin de continuar la exploración en torno a una "isla" recién descubierta y bautizada, a partir de una confusión idiomática, con el nombre de Yucatán, y de las costas aledañas. Es una relación donde además de describir el recorrido por gran parte del litoral peninsular (desde la Bahía de la Ascensión hasta la Laguna de Términos), se revela la presencia de otra isla más pequeña designada, a partir de ese momento, con su nombre maya de Cozumel y el cristiano de Santa Cruz, con el cual se indica la fecha de su primer avistamiento, el tres de mayo. Así como también se da cuenta del hallazgo de un territorio de dimensiones desconocidas, al que los nativos se referían con una voz registrada en el texto primero como Mulua y después como Uloa, en clara alusión a la palabra nahua Culúa. Es decir, la costa del Golfo de México extendida desde la Laguna de Términos hasta la región de Pánuco.

Aunada a su calidad descriptiva, en este texto se encuentra la confirmación de las impresiones de los expedicionarios de la armada descubridora conducida por el mismo piloto y capitaneada por Hernández de Córdoba, sobre la diferencia entre los aborígenes antillanos y la "gente de grande ingenio" pobladora de las nuevas regiones. ${ }^{6}$ Es decir, la valoración entre dos tipos de "indios", los salvajes

\footnotetext{
${ }^{6}$ Así califica el autor de esta relación a los mayas de Cozumel. "Itinerario", p. 286. Muchos años después, Díaz del Castillo, al recordar la primera impresión que les habían causado los pobladores de la Península a los expedicionarios de la armada de Hernández de Córdoba, escribirá que habían tenido a sus pobladores "[...] por hombres de más razón que a los indios de Cuba [...]", Historia verdadera de la conquista de la Nueva España, c. II, p. 7, Carmelo Sáenz de Santa María (ed. crít.). Madrid: Instituto Gonzalo Fernández de Oviedo y Universidad Nacional Autónoma de México, Instituto de Investigaciones Historicas, 1982, $2 \mathrm{v}$.
} 
y los que aparecen por las manifestaciones de su cultura material, observada en atuendos, armas, dimensión de las poblaciones encontradas, organización urbana y calidad de las construcciones, como representantes de una civilización comparable con las desarrolladas en la antigüedad por los pueblos del Viejo Mundo.

Los temas recurrentes a lo largo del relato resultan de un claro interés geográfico, según los estudian la geografía física y la humana, pues el autor se refiere a la habitabilidad de las tierras, su provisión de aguas, abundancia de recursos y productos comestibles, así como a la posible existencia de riqueza aurífera, pero también a las características de sus habitantes. Son estos asuntos los que parecen anunciar la formulación de las preguntas en los cuestionarios dispuestos por el Consejo de Indias para la realización, medio siglo después, de las llamadas Relaciones geográficas de Indias. ${ }^{7}$

De particular interés se muestran los juicios emitidos por el autor sobre la calidad de los distintos parajes: así mientras Cozumel le parece tierra "muy deleitosa", que emanaba a la distancia "olores tan suaves, que era cosa maravillosa", opina lo contrario de la observada entre el poblado del cacique Lázaro (Campeche) y Champotón, pues declara que "era muy baja y no nos contentó nada". Luego, si a Puerto Deseado (al que bautizan con ese nombre por las condiciones favorables para fondear las naves), también lo halla "muy deleitoso", por la "muy buena agua de pozo", la cantidad de pescado y de animales de caza, su entusiasmo se desborda al contemplar en plena primavera la desembocadura del majestuoso río, bautizado desde entonces con el nombre de Grijalva. Ante un panorama tan prometedor para la colonización lanza una expresión desmesurada: “[...] esta tierra parece ser la mejor que el sol alumbra [...]". En cuanto a los habitantes de aquel Edén tabasqueño, en armonía con el exuberante escenario natural, sólo pueden aparecer como: "hombres bien dispuestos" y "gente muy lucida". Sin embargo, la mayor sorpresa esperaba al viajero más adelante, en los linderos del dominio mexica, donde junto a la evidencia sangrienta de la práctica pagana de los sacrificios humanos, los exploradores encuentran, por fin, indicios ciertos de la existencia del oro y las riquezas tan buscadas. Pruebas que permiten al comentarista escribir: "Creemos que esta tierra es la más rica y más abundante del mundo en piedras de gran valor [...]". ${ }^{8}$

Como en general la expedición de Grijalva se ha considerado como una etapa previa al logro de la conquista de México, pero no sólo del Imperio señoreado por Tenochtitlan, sino de ese México "esencialista", del cual la historiografía liberal nacionalista decimonónica afirmaba que ha existido: "A través de los siglos", con frecuencia se ha ignorado el contexto de este viaje y su enlace con otras exploraciones, cuya finalidad última continuaba siendo, durante las primeras dé-

\footnotetext{
${ }^{7}$ Vid. Cuestionarios para la formación de las Relaciones Geográficas de Indias. Siglos XVI / XIX, Francisco de Solano (ed.). Madrid: Consejo Superior de Investigaciones Científicas, Centro de Estudios Históricos, Departamento de Historia de América, 1988.

8 "Itinerario", pp. 283, 286, 292, 294-295 y 301.
} 
cadas del siglo xvı, la búsqueda de un paso entre aquellas islas y masas terrestres, indeterminadas pero todavía supuestas como insulares, hacia el Océano Indico. ${ }^{9}$ Hallazgo con el que se daría cumplimiento al propósito colombino de encontrar por el Atlántico la ruta a las asiáticas regiones de la especiería; esas cuyos codiciados productos ya eran mercancías monopolizadas por los portugueses desde que, casi 20 años atrás, en 1499, Vasco de Gama logró completar con éxito la travesía de ida y regreso a la India, circunnavegando África.

En el sentido de la comprensión del autor del informe sobre el entorno geográfico donde navega la armada, sus observaciones no permiten reconocerlo como un experto, más bien sus nociones sobre este punto parecen ser, como las ideas de la mayoría no especializada, muy generales; por eso, cuando necesita señalar la ubicación de los navíos entre las costas, según son avistadas, recurre a la consulta de los pilotos. En el trasfondo de las descripciones del expedicionario todavía se percibe la configuración tradicional del mundo habitable formado por tres continentes unidos, rodeados por un océano salpicado de islas innumerables; de las cuales las identificadas con las legendarias Antillas se creía formaban el archipiélago más cercano al inexplorado confín oriental de la costa asiática. ${ }^{10}$ Con esta concepción el narrador entiende los informes obtenidos por medio de los intérpretes indígenas; como el testimonio de un maya de Campeche que les dio "[...] señas de un paraje donde dijo que había muchas islas, en las cuales había carabelas y hombres como nosotros, sino que tenían las orejas grandes, y que tenían espadas y rodelas, y que había allí otras muchas provincias [...]". ${ }^{11}$ Así señala cuando las naves recalan en el que llamaron Puerto Deseado, en la Laguna de Términos, lugar donde Alaminos creía encontrar la separación de la isla de Yucatán de otra "rica" llamada por los pilotos Ualor o Valor: ${ }^{12}$ "[...] por este puerto pasa un brazo de mar por el que navegan los indios con sus barcos, que llaman canoas; de esta isla pasan á rescatar á tierra firme de la India, según dijeron tres Indios que tomó el general [...] quienes afirmaron las cosas arriba dichas". ${ }^{13}$ Y más adelante

${ }^{9}$ Pedro Mártir de Anglería en su presentación al papa de la Década IV, escrita en 1520, todavía anota respecto al territorio de la futura Nueva España: "la vasta tierra Hacolucana, que aún no se sabe si es isla o continente", op. cit., v. I, p. 395.

${ }^{10}$ El tratar de comprender y explicar estos documentos desde la perspectiva del horizonte cultural de la época en que fueron escritos es una propuesta de Edmundo O'Gorman, desarrollada en su libro clásico La invención de América. Investigación acerca de la estructura histórica del Nuevo Mundo y del sentido de su devenir, $2^{\mathrm{a}}$ ed. México: Fondo de Cultura Económica, 1977.

${ }^{11}$ Los hombres de Hernández de Córdoba habían capturado a dos mayas, que llevaron a Cuba. Grijalva los aprovechó como intérpretes. El autor de la relación menciona a uno y hasta manifiesta la sospecha de que a veces los engañaba, pero no por esa desconfianza deja de anotar lo que les traducía, como este testimonio. "Itinerario”, pp. 290, 292.

12 Como ualor aparece en los textos italianos. En su traducción García Icazbalceta hace la corrección para marcar el cambio fonético entre $u \mathrm{y} v$. Aunque en la boca de la Laguna de Términos se encuentra la Isla del Carmen, esta referencia parece corresponder más bien a la península de Atasta y hasta a las propias tierras de Ulúa o Culúa.

13 “Itinerario", p. 293. Los indígenas seguramente se referían al activo comercio de canotaje que se realizaba entre el puerto de Xicalango y las costas del Golfo de Honduras. 
cuando, a pesar de haberse encontrado con altas montañas y caudalosos ríos, escribe al zarpar las naves de San Juan de Ulúa, para continuar rumbo al norte el reconocimiento de la costa: "De aquí dimos á la vela para ver si al fin de aquella sierra se acababa la isla $[\ldots]$ ". ${ }^{14}$ Es decir, aún prevalece en la mente del escritor la visión insular. ${ }^{15}$ Una idea que, desde el punto de vista cartográfico, puede ilustrarse con el mapamundi diseñado por Giovanni Matteo Contarini y grabado e impreso por Francesco Roselli en 1506, probablemente en Venecia. Carta donde, si bien se ignora el trazo de la costa centroamericana explorada durante el cuarto viaje de Colón, concluido apenas en el otoño de 1504, aparecen como novedades las islas de Cuba y La Española, además de una gran masa de tierra que se extiende desde un punto que puede ser identificado con la posición del Golfo de Urabá hasta el Golfo de Paria (desembocadura del delta del río Orinoco), y de allí a una región entre el Ecuador y el Trópico de Capricornio a la que el cartógrafo identifica con el nombre dado por los portugueses de Santa Cruz (Brasil). Pero al occidente de las Antillas se sitúan Cipango, Catay, Mangi, las islas de Java y todos los sitios asiáticos registrados en la clásica geografía de Tolomeo (figura 1). ${ }^{16}$

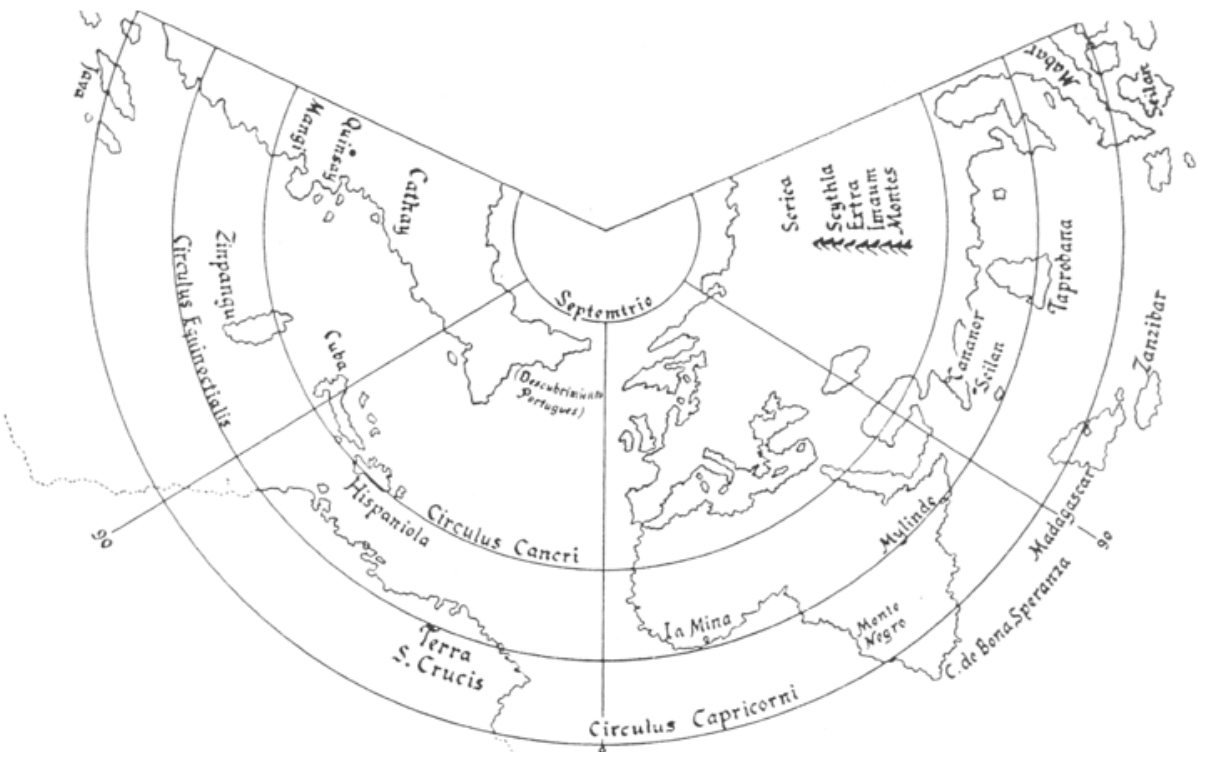

Figura 1. Croquis del mapamundi diseñado por Giovanni Matteo Contarini y grabado e impreso por Francesco Roselli en 1506.

Fuente: G. R. Crone, 1956: 112

${ }^{14}$ Ibid., p. 301.

${ }^{15}$ Vid. supra, nota 9.

${ }^{16}$ G. R. Crone, Historia de los mapas, 1956, pp. 109-111, Luis Alaminos y Jorge Hernández (trads.). México: Fondo de Cultura Económica. Croquis del mapamundi en la p. 112. 
Desde las exploraciones colombinas se había avanzado en forma significativa respecto del conocimiento de la configuración de estas regiones, pero para principios de 1518 todavía el litoral atlántico del continente no había definido su perfil como un continuo. En la primera mitad de la década anterior, las imprentas del centro de Europa se habían encargado de difundir unos opúsculos donde se anunciaba la existencia de un cuarto e inédito continente, en el hemisferio sur, descubierto por un cierto Vespucio. Luego, en 1507, se publicó la obra Cosmographiae introductio, y para acompañarla el cartógrafo Martin Waldseemüeller dibujó un planisferio que incluía el trazo de la ribera atlántica de aquella nueva tierra austral, y la bautizó con el nombre de América. ${ }^{17}$ También delineó sobre esta carta las costas de tierra firme exploradas por Colón, pero de manera incorrecta situó la provincia de Paria (Venezuela) como una superficie de menor tamaño dividida del continente austral y nada menos que cruzada por el Trópico de Cáncer. ${ }^{18}$ No obstante que de este mapa se imprimieron mil copias, ${ }^{19}$ todavía transcurrirían algunos años antes de la aceptación por la mayoría de los expertos y mucho más tiempo para la difusión general de la nueva imagen del orbe que, sin embargo, distaba aún en gran medida de la representación geográfica actual. Por otra parte, resulta pertinente advertir, al considerar la influencia del desarrollo de la cartografía en la transformación de las ideas acerca del mundo entre los lectores interesados, que por motivos estratégicos en las políticas de expansión, sobre todo de las coronas portuguesa y española, la mayor parte de los mapas elaborados desde el inicio de las exploraciones oceánicas se trató de mantener bajo estricta reserva; por tal razón los publicados aparecen trazados e impresos en ciudades independientes de aquellos reinos.

En Cuba, en el ambiente familiar de los expedicionarios, entre los cuales se encontraban algunos venidos tras el desastre colonizador de Castilla del Oro y por consecuencia enterados de las exploraciones istmeñas, la Tierra Firme estaba identificada con las costas que corrían desde el Golfo de Honduras hacia el Golfo de Paria (Venezuela) y más al sur hasta territorios que caían, por el Tratado de Tordesillas, bajo la soberanía portuguesa. Una visión que ha quedado plasmada en el mapa xilográfico añadido a la edición sevillana de 1511 de las Oceani Decas de Pedro Mártir de Anglería, donde se representan los contornos de esta isla y los de La Española, así como parte del litoral continental (figura 2). ${ }^{20}$

17 Ibid., p. 113.

${ }^{18}$ Martin Waldseemüller, Introducción a la cosmografía y las cuatro navegaciones de Américo Vespucio, Miguel León-Portilla (trad. del latín, est. introd. y n.). México: Universidad Nacional Autónoma de México, Fideicomiso Teixidor, Cátedra Guillermo y Alejandro de Humboldt y Centro de Estudios Mexicanos y Centroamericanos, 2007. En esta edición el famoso mapa se presenta tanto impreso como en una versión digital que facilita su estudio.

${ }^{19}$ Miguel León-Portilla, “Estudio introductorio”, en op. cit., p. 28.

${ }^{20}$ Vid. P. Martyris angli [sic] mediolanensis opera... Occeani [sic] decas..., Hispali, Jacobum Corumberger, 1511. Libro disponible en la página electrónica Cervantes Virtual. Jesús Varela Marcos ha estudiado los ejemplares conocidos de este mapa y propuesto que debió realizarse hasta 1514 , aunque se incluyó en reimpresiones de la edición de 1511 de las Oceani Decas. "El primer mapa impreso de América", 


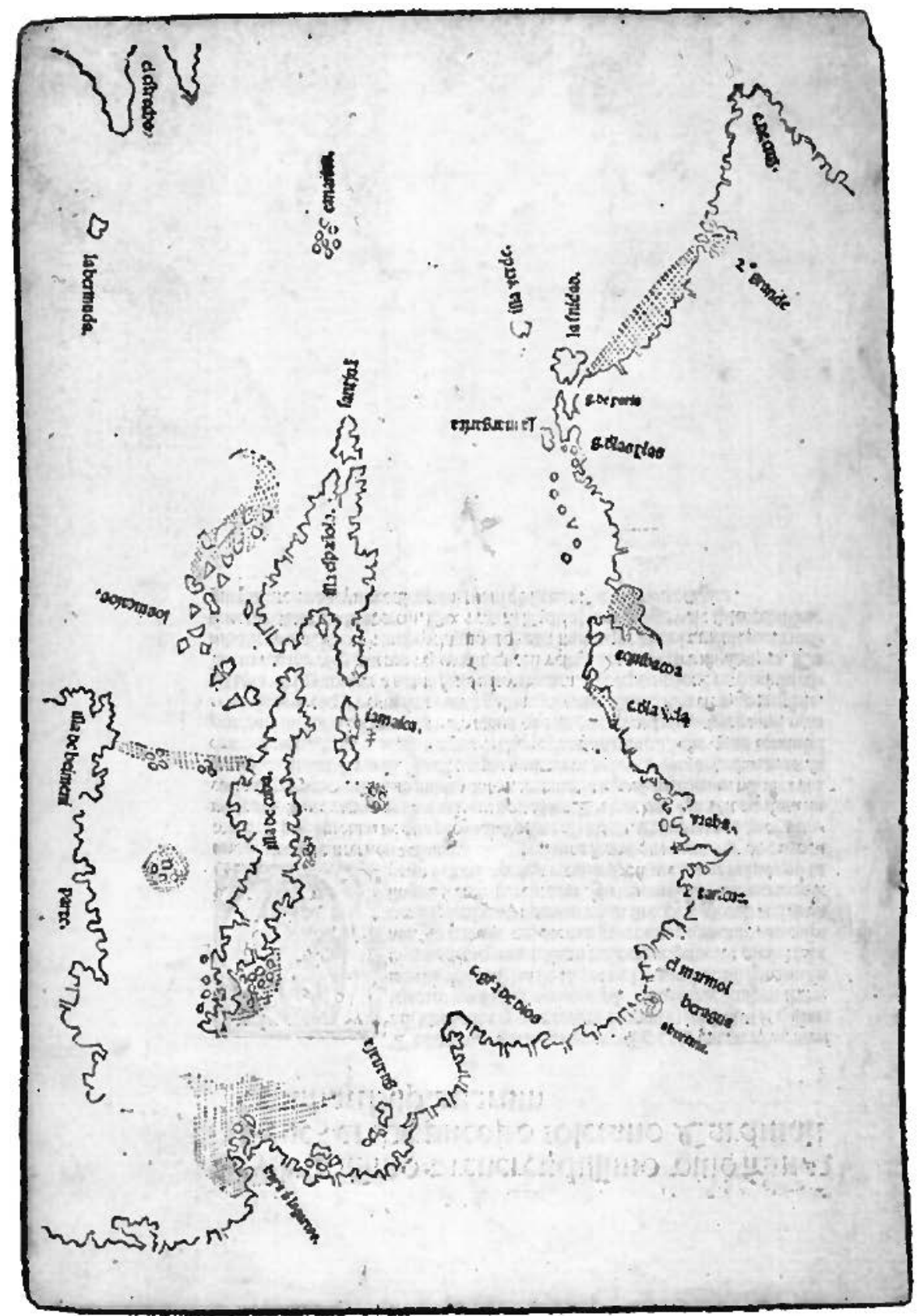

Figura 2. Mapa xilográfico aparecido en las Oceani Decas

de Pedro Mártir de Anglería editadas en Sevilla y publicadas en 1511.

Fuente: Jesús Varela Marcos, 2006: 1006 
Sólo cinco años antes del viaje de Grijalva, en 1513, se habían realizado dos importantes hallazgos. Una expedición organizada en Puerto Rico por su gobernador Juan Ponce de León, donde participó como timonel Antón de Alaminos, encontró la punta de una isla alargada o península al norte de Cuba, a la cual dio el nombre de Florida. ${ }^{21}$ Por su parte, desde el Golfo del Darién, Vasco Núñez de Balboa había cruzado la zona del istmo centroamericano y avistado un mar austral, ${ }^{22}$ piélago que llegó a suponerse confundía sus aguas con el Índico. ${ }^{23}$ En realidad un océano desconocido para los europeos, cuyas enormes dimensiones certificaría muy pronto el primer viaje de circunnavegación que, bajo la bandera española, comandó Magallanes y culminó Elcano entre 1519 y 1522.

Por aquellos meses cuando los navíos, bajo el mando de Grijalva, surcaban las aguas al occidente de las Antillas y avanzaban en el descubrimiento de la existencia de nuevas islas y costas de posibles tierras firmes, y mientras el relator de la travesía tomaba nota de sus impresiones, en España, el bachiller Martín Fernández de Enciso, alguacil mayor de la Tierra Firme de las Indias Occidentales, llamada Castilla del Oro, emprendía la composición del primer tratado de geografía y "arte del marear" escrito, en castellano, con un propósito didáctico. Era el autor una amalgama de hombre de letras y de acción, estudioso independiente de los círculos académicos universitarios, dueño de una mente abierta a la observación y la experimentación, pero sobre todo, práctico en cuestiones indianas. ${ }^{24}$ Para

El Mediterráneo y América, Actas del XI Congreso Internacional de la Asociación Española de Americanistas, v. II, pp. 995-1007. Murcia: Editora Regional de Murcia, 2006. Este estudio se puede consultar en la página electrónica < http://www.americanistas.es/biblo/textos/11/11-68pc >. En el presente trabajo se reproduce el mapa publicado por Varela en la p. 1006. Cabe señalar que los subrayados que incorporé en éste y otros títulos, así como en algunas citas, corresponden a letras restituidas en palabras que aparecen abreviadas en los impresos.

${ }^{21}$ Registrada en el mapa xilográfico como Isla de Beimeni por confusión con una de las islas Bimini de las Bahamas.

22 Pedro Mártir de Anglería, con base en los informes recibidos desde el Darién, relata en sus Décadas II y III, escritas entre 1514 y 1516, los antecedentes y la realización del célebre descubrimiento, inspirado por los informes de un hijo del gobernante Comogro que, en un pasaje digno de citarse aquí por su semejanza con los mencionados del "Itinerario", les dice a los hombres de Balboa: "Una vez cruzados esos montes [...] os será lícito contemplar otro mar surcado por veleros no menores que los vuestros (y mostraba las carabelas), pues aunque sus naturales anden desnudos como nosotros saben servirse de velas y remos. Todo aquel lado que mira al sur, desde las aguas vertientes de las montañas, produce oro en abundancia”, op. cit., Década II, lib. III, v. I, p. 235.

${ }^{23}$ En el libro IX de la Década II, Pedro Mártir refiere cómo se suponía que el mar visto por Balboa se mezclaba con el de la India; y en el libro I de la Década III, lo menciona como uno antes ignorado. Ibid., v. I, pp. 275 y 287.

${ }^{24}$ Las andanzas probadas de Fernández de Enciso por el Nuevo Mundo transcurrieron en dos momentos. Del primero fue testigo Bartolomé de Las Casas a partir de 1509, cuando en Santo Domingo el bachiller se asoció con Alonso de Hojeda para invertir en el financiamiento de la expedición destinada a establecer en el Darién la gobernación de la Nueva Andalucía. El capitán lo nombró alcalde mayor de la futura colonia, a cambio del compromiso de avituallar un navío y conducirlo después hasta donde se asentara Hojeda. Sin noticias acerca de la suerte corrida por los expedicionarios, diezmados por las flechas envenenadas de los naturales de la región de Cartagena y divididos tras el fracaso en el establecimiento en el Golfo de Urabá, e ignorante del intento fallido por regresar a La 
la mejor comprensión de su libro, trazó un planisferio donde integró los conocimientos de la cosmografía tradicional con las aportaciones de la exploración oceánica, llevada a cabo desde el viaje inicial de Colón hasta el descubrimiento del incógnito mar austral. Como este mapa no se ha conservado o está perdido, de sus conocimientos y habilidad cartográfica dan razón las descripciones del propio texto. Es pertinente mencionar además que durante su estancia en Santo Domingo conoció a Juan de la Cosa, el autor de la primera carta universal donde se registran los descubrimientos realizados bajo el patrocinio de España, Portugal o Inglaterra, dibujada en $1500 .{ }^{25}$ Aunque la obra del bachiller haya sido terminada después del informe escrito sobre la segunda travesía dirigida por el piloto Alaminos desde Cuba, bien puede considerarse como una introducción eficaz para entender la imagen del mundo subyacente en las descripciones allí contenidas.

En 1519, la imprenta de Jacobo Cronberger editó el texto en Sevilla, bajo el título:

Suma de geographia que / trata de todas las partidas \& prouin / cias del mundo: en especial de las in / días. \& trata largamente del arte del mare / ar: juntamente con la espera [sic por esfera] en romance: / con el regimiento del sol \& del norte: nue / uamente hecha. / Con preuilegio real. ${ }^{26}$

A esta impresión siguió una segunda corregida, también estampada en la misma ciudad andaluza, ahora por Juan Cronberger, después de la muerte del autor, y ya cuando podía considerarse una obra atrasada en cuanto a los significativos avances en la determinación de la geografía continental, ocurridos en los últimos

Española y naufragio de Hojeda en Cuba, Enciso zarpó llevando en el barco como polizón a quien se convertiría en su acérrimo enemigo: Vasco Núñez de Balboa. En Tierra Firme enfrentó toda clase de calamidades: naufragios, hambre, batallas con los nativos y discordias con los expedicionarios, que terminaron por desconocer su autoridad y lo desterraron de la villa de Santa María de la Antigua, que había fundado, tras lo cual naufragó en Cuba. Vid. Historia de las Indias, lib. II, c. LII, LXII-LXIV; lib. III, c. XXIV, v. II, pp. 376, 407-416, 519-520, Agustín Millares Carlo (ed.), Lewis Hanke (est. prel.). México: Fondo de Cultura Económica, $2^{\text {a }}$ ed., 1965. Cuando regresó a España para presentar sus querellas ante el Consejo, fue huésped de Pedro Mártir de Anglería. El lombardo aprovechó sus informes para escribir los libros I al IV, VI y VII de la segunda década, compuesta en 1514 y publicada en 1516. Op. cit., v. I, pp. 209-283. De la vuelta de Enciso al Darién, en 1514, fue testigo su amigo Gonzalo Fernández de Oviedo pues ambos formaron parte de la armada de Pedrarias Dávila. Vid. Historia general y natural de las Indias, lib. X, c. XVII, v. III, p. 277, Juan Pérez de Tudela (ed. y est. prel.). Madrid: Atlas, 1959, $5 \mathrm{v}$.

${ }^{25}$ Vid. Luisa Martín-Merás, "La carta de Juan de la Cosa: interpretación e historia", Monte Buciero, 4: 71-86. Artículo disponible en la dirección electrónica <http://dialnet.unirioja.es/descarga/articulo/206305.pdf > .

${ }^{26}$ El grabado de esta portada, donde aparece la figura de la esfera sostenida por una mano con su brazo entre las representaciones antropomorfas de la luna y el sol, se reproduce en la entrada correspondiente a Martín Fernández de Enciso en la página electrónica de Wikipedia. La enciclopedia libre. También ofrece su texto Agustín Millares Carlo en el "Índice analítico" de la Historia de las Indias de fray Bartolomé de Las Casas, op. cit., v. III, p. 450. 
dos lustros, pero no respecto de la utilidad de sus explicaciones como un instructivo o guía práctica para los marinos, en $1530,{ }^{27}$ un año importante para la historia de la difusión del conocimiento sobre el Nuevo Mundo, pues entonces se editaron por fin completas las Décadas de Pedro Mártir de Anglería. ${ }^{28}$

Con buen sentido de la oportunidad política y tal vez interesado en conseguir alguna promoción en el servicio real o el simple reconocimiento de sus méritos y el patrocinio para imprimir su libro, el alguacil mayor dedicó este trabajo al recién electo emperador don Carlos, "Señor de las indias ocidentales", por ser "[...] a quien mas pertenesce saber las prouincias \& cosas del vniuerso: y lo que en cada vna ay $\&$ a donde cae [...]". ${ }^{29}$ Cómo un maestro lo haría con su discípulo, además de permitirse exhortarlo con el ejemplo de Alejandro Magno para que ocupara su juventud en procurar expandir los dominios de la Corona española, el bachiller le ofreció una lección que consideraba de especial pertinencia en razón de las responsabilidades adquiridas por el bisoño soberano con la dignidad imperial. Así le explica el plan de la obra y la conveniencia práctica de utilizarla para proyectar los viajes de descubrimiento, en un párrafo que parece anunciar, una vez más, la temática de los cuestionarios que orientarán las futuras relaciones geográficas proyectadas para racionalizar el gobierno del imperio:

E por dar claridad desto a los nauegantes porque mejor pudiessen hazer lo que por vuestra Magestad les fuesse mandado y encomendado puse en esta suma las costas de las tierras por derrotas \& alturas nombrando los cabos de las tierras y el altura $\&$ grados en que cada vna esta y en el paraje de cada costa nonbre el rio que en ella entra en la mar y las sierras y montes de donde nasce: \& las prouincias por donde passa: y de que qualidad es la gente de cada prouincia: y de que ley o seta: y que frutos y cosas y metales ay en cada vna porque vuestra magestad pudiesse en suma breue mejor oyr leer todas las prouincias del vniuerso de que fasta oy se han

\footnotetext{
27 Suma de geographia que / trata de todas las partidas \& prouinci / as del mundo: en especial de las indias. / \& trata largamente del arte del marear / juntamente con la espera [sic] en romance: / con el regimiento del sol y del norte: ago / ra nueuamente emendada de algunos / defectos que tenia en la impression passada. Libro disponible en la página electrónica Cervantes Virtual. Ejemplar resguardado en el Fondo Antiguo y Colecciones Singulares de la Universidad de Valencia. A esta edición corresponden las citas del presente trabajo. La Suma todavía volvió a imprimirse en Sevilla en 1546, en tal ocasión a cargo del tipógrafo Andrés de Burgos. Dicha edición también se puede consultar en la página electrónica citada.

${ }^{28}$ De orbe no / uo Petri Martyris ab / Angleria Mediolanen / sis Protonotarii / Cesaris sena / toris de / cades. / Cum priuilegio Imperiali. / Compluti apud Micha / elen de Eguia, anno / M.D.XXX. Libro disponible en la página electrónica Internet Archive. Acerca de la vida de este humanista y el proceso de composición de sus Décadas véase María del Carmen León Cázares, "Pedro Mártir de Anglería”, La creación de una imagen propia. La tradición española. Historiografía mexicana, v. II, t. I, pp. 165-195. México: Universidad Nacional Autónoma de México, Instituto de Investigaciones Históricas, 2012.

${ }^{29}$ Fernández de Enciso, op. cit., f. II. Henry Harrisse, en su Bibliotheca, n. 97, p. 167, registra la fecha del privilegio real otorgado en Zaragoza el 5 de septiembre de 1518, lo que prueba que la dedicatoria al rey Carlos como emperador fue escrita o corregida meses más tarde, al conocerse en España la decisión de los electores en julio del año siguiente. Vid. Pedro Mártir de Anglería, “Epistolario”, José López de Toro (est. y trad.), Documentos inéditos para la historia de España, v. IX, carta 643. Barcelona, 15 de julio de 1519, pp. 364-365, 1956.
} 
sabido por los de nuestra Europa \& saber lo que en cada vna ay. y de que qualidad es la gente y de que ley o seta: porque esto visto pudiesse mejor deliberar vuestra magestad lo que al seruicio de dios y de vuestra magestad conuiniesse para hazer descobrir \& ganar las tierras que por las gentes que no son christianos estan ocupadas porque nuestra sancta fe catholica fuesse mas acrecentada. ${ }^{30}$

En el colofón, el bachiller menciona los autores y las obras que le sirvieron de fundamento para componer la Suma. Junto a las imprescindibles autoridades cosmográficas de la antigüedad, a saber: Tolomeo, Eratóstenes, Plinio y Estrabón, como hijo legítimo de su tiempo y circunstancia, añade: "[...] la experiencia de nuestros tiempos que es madre de todas las cosas". ${ }^{31}$ Con una actitud que, a la vuelta de unos cuantos años, se convertirá en el argumento primordial de Gonzalo Fernández de Oviedo, en su afán por demostrar la validez de lo que escribe en la Historia general y natural de las Indias. ${ }^{32}$

La Suma consta de dos secciones: la primera dedicada a la explicación de la configuración y funcionamiento del cosmos, según el sistema geocéntrico, con las reglas para realizar los cálculos matemáticos necesarios a fin de orientarse en las travesías náuticas, y la segunda a la descripción geográfica. En ésta, el autor divide el mundo, de polo a polo, en dos mitades, a partir del meridiano "fijo" que se suponía pasaba por la isla del Hierro, la más occidental de las Canarias. En la mitad oriental coloca Europa, África y Asia, donde hace la distinción con la India oriental como algo diferente, y en la otra las llamadas Indias occidentales divididas en dos: las tierras septentrionales, identificadas con El Labrador y las costas de los bacalaos, al norte de las Azores, y las que se sitúan hacia el austro, donde señala que hay una porción mayor de tierra descubierta. ${ }^{33}$

${ }^{30}$ Fernández de Enciso, op. cit., f. II-Ilv.

${ }^{31}$ Millares, loc. cit. El resto de sus referencias bibliográficas está compuesto por la Biblia, Flavio Josefo, y san Anselmo, además de dos obras cuya identidad sólo podemos suponer: una Historia general que tal vez fuera la realizada por los historiógrafos de Alfonso X, pues una copia de la misma aparece registrada en Sevilla (véase María del Carmen Álvarez, "La biblioteca de don Fadrique Enríquez de Ribera, I Marqués de Tarifa (1532)”, Historia, Instituciones, Documentos, 13: 17. Artículo disponible en la dirección electrónica <http://dialnet.unirioja.es/descarga/articulo/58190.pdf>, y otra que cita como Historia Batriana, es decir, Bactriana, de donde tomaría Enciso la información que ofrece sobre las expediciones de Alejandro Magno, posiblemente el libro de Quintus Curtius Rufos, Historiae Alexandri Magni Macedonis, pues una edición de 1491, impresa en Verona, aparece registrada por Carmen M. Jiménez-Castellanos en el "Catálogo de incunables de la Biblioteca Capitular de Sevilla”, Historia, Instituciones, Documentos, 9: 214. Artículo disponible en la dirección electrónica < http://dialnet.unirioja. es/descarga/articulo/58145.pdf>.

32 Fernández de Oviedo, op. cit., lib. I, proemio, v. I, p. 11. La influencia de Fernández de Enciso es evidente tanto en esta obra como en el Sumario del mismo autor. Acerca de la vida y escritos del cronista indiano véase: María del Carmen León Cázares, “Gonzalo Fernández de Oviedo y Valdés”, La creación de una imagen propia. La tradición española. Historiografía mexicana, v. II, t. I, pp. 197-234. México: Universidad Nacional Autónoma de México, Instituto de Investigaciones Históricas, 2012.

${ }^{33}$ Enciso se refiere en tres ocasiones a la división del mundo, op. cit., f. II, XXIIII y Lv [vale advertir que del folio LX en adelante hay errores en la numeración. Así, este L $v$ corresponde al LXIIv]. 
De especial significado para comprender la posible imagen del mundo de quienes navegaban por el Caribe y el futuro Golfo de México resulta lo que el bachiller escribe sobre la India oriental en el extremo de Asia. A esa India, considerada mucho más extensa que el subcontinente que hoy conserva este nombre, la divide en tres partes, de occidente a oriente: la primera de Persia al Río Indo, la segunda del anterior hasta el Ganges y la tercera de la misma corriente hasta el Gatigara. De la última señala que se trata de "[...] la mayor \& la mejor \& la mas rica de todas". ${ }^{34}$ Si bien, no deja de advertir que era una tierra casi desconocida:

[...] la postrera india a que llaman catayo [China] \& a do fueron las tierras del preste juan \& la de Got y magot no ay escriptura autentica mas de la del rey sodiano [¿Sogdiano de Persia?]: porque si algunos mercaderes han pasado alla han visto poco y aquello escriuenlo dudoso $\&$ poco $\&$ sin orden: $\&$ assi es todo de poca fe. ${ }^{35}$

Respecto de la forma del extremo occidental del continente asiático, cuyas costas se creía bañaba el Atlántico, el bachiller adopta la teoría que afirmaba la existencia de dos penínsulas, separadas por el Maremagnum, alargadas de norte a sur, la segunda tan prolongada que finalizaría más allá del Trópico de Capricornio, a las que identifica respectivamente con el Quersoneso Áureo y la región de Gatigara. ${ }^{36}$ A continuación puntualiza:

Desde aqui adelante no ay noticia de mas tierras porque no se ha nauegado mas adelante: \& por tierra no se puede andar porque la tierra es toda lagos y de grandes montañas muy altas: a do se dize que es el parayso terrenal a do esta la fuente do nascen los quatro rios en cruz[...] esta tierra toda se llama el Catayo \& dizen que es la final tierra del oriente porque no ay noticia de alli adelante de otras tierras. ${ }^{37}$

El autor vuelve a situarse en la isla del Hierro para dedicar el último apartado de su trabajo a las Indias Occidentales. Primero da cuenta de los hallazgos de Portugal, por eso toma la isla de San Nicolás del archipiélago de Cabo Verde como punto de partida para luego atravesar el océano y marcar las distancias en el litoral del Brasil por debajo del Ecuador, desde el Cabo de San Agustín hasta el de Santa María, próximo a la desembocadura del Río de la Plata. De nuevo con el Cabo de San Agustín como referencia, en dirección contraria, hace el reconocimiento de las islas y costas descubiertas por la corona española, al norte de la línea equinoccial, con especial atención en las características de los puertos y de los pobladores, belicosos o pacífi-

${ }^{34}$ Ibid., f. XLIXv [LXIv].

35 Ibid., f. LIXv. Vale recordar que Catayo o Catay era la parte de China visitada por Marco Polo.

${ }^{36}$ Enciso identifica Gatigara con la tierra de los unicornios y la sitúa a 9 o 10 grados al sur del Ecuador, próxima a la isla de Java Menor, Ibid., f. L [LXII]. En el mapamundi de Waldssemüller aparece como Catigara en la costa de la segunda península, de cara al Maremagnum y frente a la punta del Quersoneso Áureo. Cfr. "Cosmografía universal según la tradición de Ptolomeo y los descubrimientos de Américo Vespucio y de otros", Martín Waldseemüller, op. cit. Para abundar en la explicación de las teorías sobre las penínsulas asiáticas y su relación con los viajes de Colón, vid. O'Gorman, op. cit., pp. 64-68.

${ }^{37}$ Fernández de Enciso, op. cit., f. L [LXII]. 
cos. Describe la desembocadura del Marañón (Río Amazonas), el llamado Mar Dulce y algunas costumbres de sus habitantes. Luego ofrece información sobre la provincia de Paria, su golfo, la Isla de Trinidad y los guerreros nativos que la resguardan. Deja allí la línea costera para registrar las Antillas Menores, habitadas por caníbales, y seguir a las islas colonizadas o en proceso de serlo, como San Juan de Puerto Rico, La Española, Cuba, las Lucayas y Jamaica, con la descripción de sus características naturales, las riquezas que se producen y las costumbres de los naturales. De especial interés resulta el señalamiento que hace respecto de que: "[...] al norueste del fin de cuba se ha parescido vna tierra grande que creen que es tierra firme", ${ }^{38}$ una referencia algo desviada pero segura de la Florida. Vuelve a la ribera de Paria para seguirla hacia el oeste, de la isla Margarita al Golfo de Venezuela, y luego rumbo al sur los litorales de Santa Martha, Cartagena y el puerto de Cenu (desembocadura del Río Sinú), donde había experimentado la furia de los indios flecheros y la resistencia de los caciques para aceptar el Requerimiento. ${ }^{39}$ Continúa con la descripción del Golfo de Urabá y el litoral de Veragua que se prolonga hacia el norte hasta el cabo Gracias a Dios (en la frontera actual entre Nicaragua y Honduras), donde la costa empieza a correr hacia el oeste. Entre los accidentes geográficos identificables allí mencionados aparecen la punta de Caxinas y la Bahía de Santo Tome (posiblemente Santo Tomás de Castilla en la Bahía de Amatique, lugar donde empieza la ribera caribeña de la península de Yucatán). El último punto que señala en los $21^{\circ}$ es el cabo de las Figueras o Higueras, y dice: "Desde aqui se boluieron los descobridores que no pasaron mas [...] \& hallaron señales que auia mucho oro: porque hallauan grandes pieças de oro en poder de los indios" ${ }^{40}$ En segura referencia a Juan Díaz de Solís y Vicente Yañez Pinzón, los cuales en 1507 descubrieron la Bahía de Amatique mientras reconocían el Golfo de Honduras, en busca del estrecho que permitiría el paso al Océano Índico. ${ }^{41}$ A continuación regresa al Golfo de Urabá para cruzar el istmo que lo separa del Golfo de San Miguel, en la Mar del Sur, y dar razón de la Isla de las Perlas y lugares aledaños del Golfo de Panamá, recién abiertos a la exploración.

Fernández de Enciso debe haber entregado a la imprenta el texto de la Suma en el verano de 1519, cuando se tuvo conocimiento en España de la elección del emperador; poco antes de que empezaran a divulgarse, fuera del círculo cortesano, las noticias sobre los hallazgos de las dos primeras expediciones organizadas en Cuba, por eso su obra constituye un testimonio fundamental de la imagen del Nuevo Mundo tal y como se percibía a principios de 1517, todavía sin la presencia de la península de Yucatán ni del amplísimo litoral que la enlazaba con la punta de la Florida. ${ }^{42}$

${ }^{38}$ Ibid., f. LIIII [LXVI].

${ }^{39}$ Ibid., f. LVv [LXVIIv].

${ }^{40}$ Ibid., f. LVII $v$ [LXIXv]. Es pertinente señalar que la cuenta de los grados propuesta por el bachiller no corresponde con los cálculos actuales, pues en $21^{\circ}$ lo que se encuentra es Isla Mujeres en la costa de Quintana Roo.

${ }^{41}$ Fernández de Oviedo, op. cit., lib. XXI, c. VIII, v. II, p. 329.

42 Por las fechas de las cartas de Pedro Mártir de Anglería se sabe que para julio de 1518 ya se tenía noticia en la corte del resultado de la expedición de Hernández de Córdoba, y de que para el mismo 
Como resultado de las exploraciones por el Golfo de México y las tierras aledañas se elaboraron dos mapas. Éstos fueron los primeros donde se delineaba completa la ribera continental desde Honduras hasta la Florida, al eslabonar los últimos descubrimientos colombinos con los hallazgos más recientes.

El más antiguo registra los resultados de las exploraciones realizadas, en 1519, por la armada bajo la capitanía de Alonso Álvarez Pineda, en nombre del gobernador de Jamaica Francisco de Garay, a partir de la región de Pánuco, reconocida un año antes por Alaminos, y sobre las costas que se extendían formando un gran arco rumbo al noreste cerrado por la Florida (figura 3). ${ }^{43}$ Se trata de un dibujo muy elemental que sirve de soporte a una toponimia con propósito orientador, pero también a una serie de anotaciones sobre los puntos visitados por esta expedición. La leyenda más larga señala los límites entre las tierras descubiertas bajo la autoridad de Velázquez y las exploradas por cuenta de Garay. Entre sus trazos resulta de particular interés la figura con que se representa a Yucatán como una península demasiado alargada y a Cozumel como una islita perdida en medio del Caribe sin relación con la costa.

El otro es el muy conocido grabado que acompañaba la edición latina impresa en Nuremberg, en 1524, de la segunda y tercera Cartas de Relación de Hernán Cortés al emperador, fechadas en 1520 y 1522 . Consta de dos secciones: una representa el contorno del Golfo y la otra la ciudad de Tenochtitlan rodeada por su laguna. En la primera se señalan con el nombre dado por los exploradores varios accidentes geográficos, sobre todo las desembocaduras de los ríos, desde la Punta de las Higueras hasta la Florida, además del cabo occidental de Cuba en medio de los dos extremos. Aquí Yucatán aparece dibujado como una isla de contorno caprichoso, más detallada en la costa norte. Cozumel se distingue por su tamaño, junto a otras más pequeñas. Cerca de Cabo Catoche se marcan dos isleos como para representar Isla Mujeres. A la entrada de la Laguna de Términos se señala la Isla del Carmen y se delinea la península de Atasta como si se tratara de otra isla de mayores dimensiones. Al comparar este mapa con la relación del viaje de Grijalva, los puntos de acuerdo entre el texto y la imagen resultan sorprendentes, sobre todo en la parte correspondiente a la Laguna de Términos, pues su disposición además concuerda con el testimonio de los naturales (figura 4). ${ }^{44}$

mes del siguiente año era ya conocido que el rey Carlos había sido electo emperador. Vid. "Epistolario", v. XI, carta 623, Zaragoza, 21 de julio de 1518, pp. 324-325 y carta 643. Vid. supra, nota 29.

${ }^{43}$ Este mapa permaneció inédito hasta el siglo XIX, pero Pedro Mártir ofrece su descripción inicial en el libro primero de la quinta década. Décadas..., v. II, p. 443. Aquí se reproduce de la manera en que fue publicado en The discovery of New Spain in 1518 by Juan de Grijalva, a translation of the original texts whit and introduction and notes by Henry R. Wagner. Pasadena: The Cortés Society, 1942. Frontispiece. El mismo autor informa que se conserva en el Archivo General de Indias, que Fernández de Navarrete lo dio a conocer, y que Paso y Troncoso insertó el facsimilar en su edición de la Crónica de Cervantes de Salazar, p. 2.

${ }^{44}$ Vid. supra, nota 13. En este trabajo se reproduce la primera sección del mapa como fue publicado en The discovery..., p. 54. 


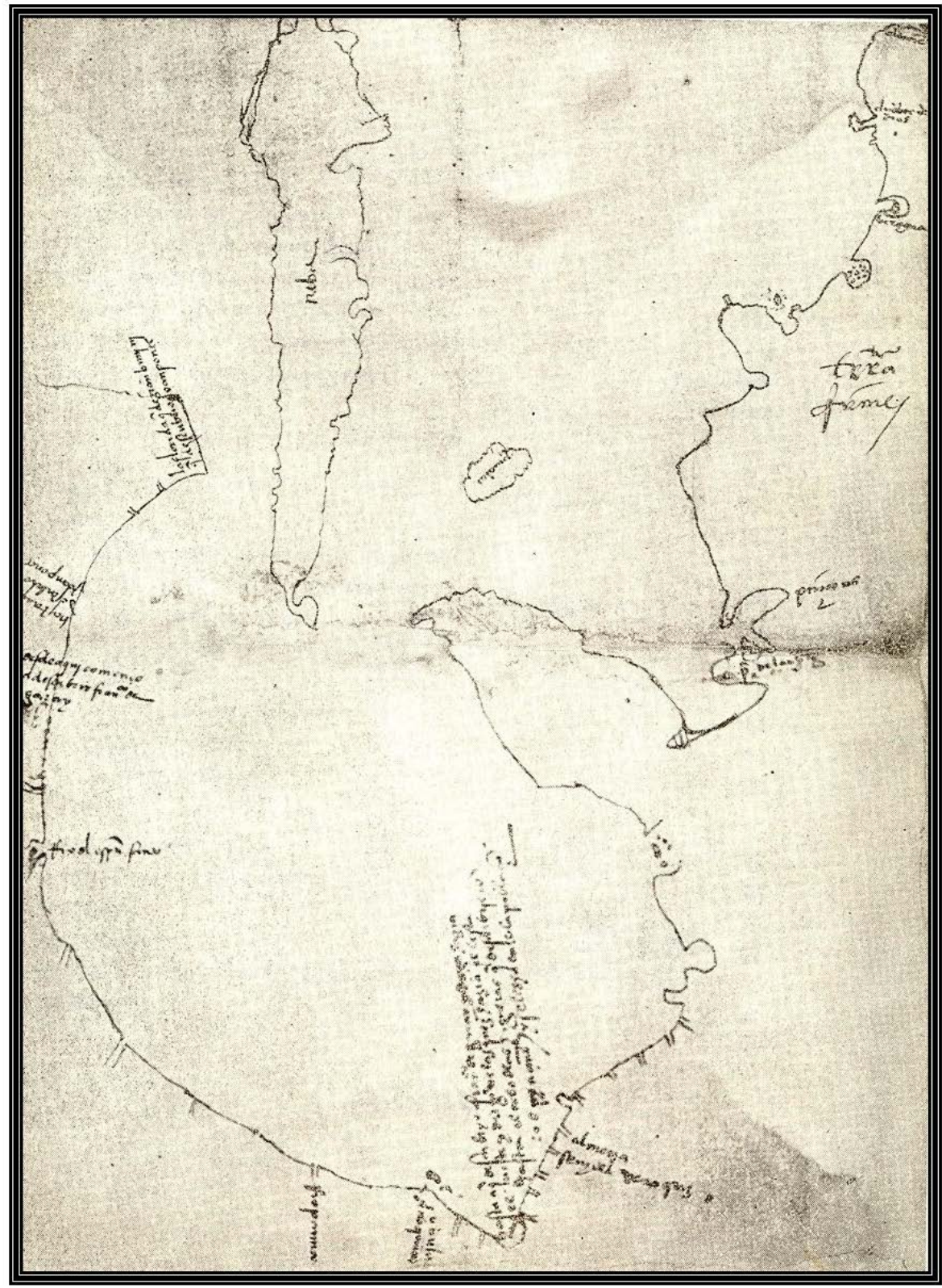

Figura 3. Mapa del Golfo de México elaborado a partir de los hallazgos de la expedición de 1519, comandada por Alonso Álvarez Pineda. Fuente: Henry R. Wagner, 1942: Frontispiece 


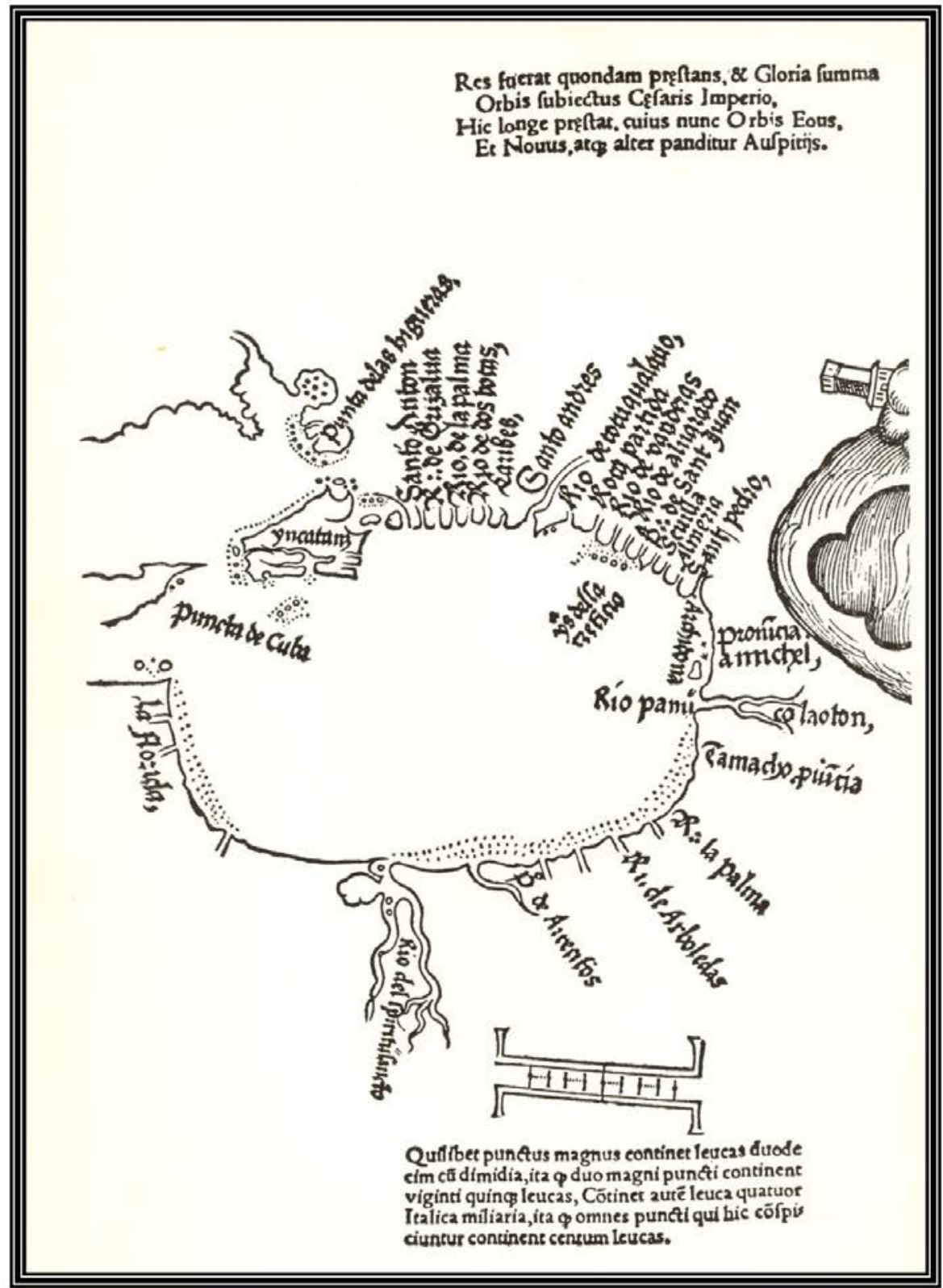

Figura 4. Mapa del Golfo de México publicado con la Segunda

y Tercera Cartas de Relación de Hernán Cortés en Nuremberg en 1524.

Fuente: Henry R. Wagner, 1942: 54 
Si bien, el avance de los descubrimientos era asimilado por una cartografía cada vez más realista, en las casi siempre atinadas observaciones geográficas del autor de este informe, como había sucedido con otras descripciones de las supuestas innumerables islas oceánicas, todavía tuvieron cabida los mitos heredados de la antiguiedad clásica; en su caso el de la existencia de las amazonas, ahora personificado por unas imaginarias mujeres que habitarían solas una punta en la costa norte de Yucatán, en referencia indudable a Isla Mujeres; así bautizada desde el viaje comandado por Hernández de Córdoba, debido a las imágenes de las deidades femeninas de los mayas que allí fueron descubiertas. ${ }^{45}$ Una mezcla entre realidad y fantasía nada sorprendente de encontrar en el pensamiento de los exploradores, cuando todavía el propio Fernández de Enciso, tan preocupado por señalar siempre lo que tiene por fábula, acepta con frecuencia como verdaderos no pocos mitos.

\section{III}

Al considerar el contexto político en que se organizó la expedición de Grijalva, no parece aventurado afirmar que el autor escribiera esta relación, más que como respuesta a una motivación personal, en cumplimiento de un encargo expreso de Diego Velázquez, con el propósito definido de documentar ante la Corona sus pretensiones respecto a la futura jurisdicción de unas tierras tan prometedoras de riquezas. Si bien el comandante tendría la obligación de dar cuenta al promotor de la armada sobre los resultados, en aquellas circunstancias, cuando había un interés tan grande en juego, era muy conveniente contar además con un informante de lealtad comprobada. El autor viaja a bordo de la nave capitana cerca del piloto mayor y conforme avanza la expedición sus comentarios se convierten en abierta censura al ineficiente desempeño de Grijalva para tomar decisiones encaminadas a obtener mayor provecho económico; como también lo responsabiliza, sin razón, pues sólo estaba siguiendo órdenes de su superior, por haber impedido el establecimiento de enclaves colonizadores.

En cuanto al momento de redacción del informe, su composición indica que fue escrito como un diario, en primera persona del plural, según ocurrían los acontecimientos que el autor juzgaba dignos de anotarse, pues o bien registra las fechas o los días transcurridos entre los sucesos, aunque se observa una mayor precisión desde el avistamiento de Cozumel hasta el arribo de la armada a la Isla de Sacrificios. ${ }^{46}$ La relación comienza con la salida de Cuba, todavía llamada la

\footnotetext{
45 Diego de Landa, Relación de las cosas de Yucatán, María del Carmen León Cázares (est. prel., cronolog. y rev.). México: Consejo Nacional para la Cultura y las Artes, 1994, p. 89.

${ }^{46}$ La última fecha registrada es el 8 de junio, que señala el descubrimiento del Río Grijalva. "Itinerario", p. 293.
} 
"isla Fernandina”, el primero de mayo, y concluye en el "puerto de San Cristóbal”, con el regreso de la expedición, probablemente el 30 de septiembre de $1518 .{ }^{47}$

El teniente de gobernador Diego Velázquez, sin recibir todavía noticias sobre la concesión del nombramiento que había pedido como adelantado de las tierras descubiertas por Hernández de Córdoba, se apresuró a enviar a su capellán, Benito Martín, para que con el peso de las nuevas evidencias continuase la negociación con la Corona para obtenerlo. ${ }^{48}$ Tal solicitud estaba acompañada, entre otros documentos, como un informe redactado por el propio Grijalva, por esta relación y por una muestra de las riquezas encontradas. ${ }^{49}$ Se sabe, gracias al testimonio de Fernández de Oviedo, que el emisario estaba ya en la corte, en Barcelona, en la primavera de $1519 .{ }^{50}$ En los datos que Las Casas aporta respecto de las diligencias efectuadas por este clérigo, a lo largo de aquel año, ante los funcionarios reales, aparece de nuevo la visión insular que todavía era predominante acerca de las tierras recién exploradas, pues Martín presentó una petición para que el rey le concediese la abadía de la región descubierta: "[...] adelante de Culuá [sic], estimando también que era isla [...] que no salió menos que ser toda la Nueva España [...]". ${ }^{51}$

El original en castellano de esta relación ha estado perdido, al igual que sucede con el informe escrito por el capitán, desde el siglo xvı, pero su contenido logró conservarse y difundirse entre los lectores europeos gracias a que, de manera simultánea y casi de inmediato, fue objeto de varias ediciones y traducciones, además de convertirse en fuente de información para Pedro Mártir de Anglería, el primer cronista indiano y uno de los escritores de mayor éxito editorial dentro y fuera de España en su momento, y para Gonzalo Fernández de Oviedo. ${ }^{52}$

${ }^{47}$ Ibid., p. 306. Gonzalo Fernández de Oviedo relata con muchos pormenores el viaje de regreso a Cuba y anota el desembarco del capitán en la villa de San Cristóbal ese día. Op. cit., lib. XVII, c. XVIII, v. II, p. 147.

${ }^{48}$ Las Casas informa que Velázquez, desde el regreso de la primera expedición, había enviado procuradores a la Corte, Gonzalo de Guzmán y Pánfilo de Narváez, para solicitar el cargo de adelantado sobre las tierras recién descubiertas. El Consejo se lo concedió mediante una capitulación fechada en Zaragoza el 13 de noviembre de 1518. Op. cit., lib. III, c. CXXIV, v. III, pp. 255-259.

49 "Itinerario", pp. 306-307, en esta versión se menciona el informe de Grijalva.

${ }^{50}$ En los capítulos que Fernández de Oviedo dedica a la exploración de Grijalva señala varios lugares y momentos donde el escribano de la armada levantó testimonio de los actos de carácter jurídico, como en la toma de posesión en Cozumel o la declaración de Alaminos, en Puerto Deseado, de no poder continuar la navegación, desde Términos a la Bahía de la "Asumpción" [sic por Ascensión], para reconocer todo el litoral de la "isla” de Yucatán, porque el tamaño de los navíos le impedía avanzar por una mar tan baja. Autos que Velázquez después envío a España. Op. cit., lib. XVII, c. IX y c. XII, v. II, p. 120 y p. 131. Además de algunos de los documentos, el cronista también afirma haber visto entonces "muchas de aquellas muestras y cosas", loc. cit., c. XIX, p. 148.

${ }^{51}$ Las Casas, op. cit., lib. III, c. CXVIII, v. III, p. 233, refiere la controversia entre este clérigo y fray Julián Garcés por los beneficios eclesiásticos que habían de fundarse en las nuevas tierras cuando aún se desconocían sus verdaderas dimensiones. Martín no llegó a gozar de prebenda alguna pues murió en el viaje de regreso a Cuba. Todavía, a su paso por Sevilla, alcanzó a conocer a los procuradores de Cortés y denunció ante el obispo Fonseca el alzamiento de este capitán contra Velázquez. Loc. cit., c. CXXIII, p. 255.

${ }^{52}$ Mártir de Anglería lo utilizó para documentar los libros III y IV de su IV Década, cuya información vio la luz al publicarse su famoso Epítome en 1521. Fernández de Oviedo lo aprovechó, junto 
Se ignora cómo este relato, o con más probabilidad una copia del mismo, llegó a manos del conocido editor milanés Zorzi o Giorgi di Rusconi, que lo publicó en Venecia, traducido al toscano, en una fecha tan temprana como fue el 3 de marzo de $1520 .{ }^{53}$ Entonces, la relación apareció incorporada como complemento del Itinerario de Ludovico de Varthema. Una crónica difundida en numerosas ediciones y traducciones, desde la impresa en Roma en 1510, donde este aventurero boloñés, famoso a consecuencia del viaje que había realizado entre 1503 y 1508 por distintas regiones de África y Asía, narraba su paso por Egipto, Siria, Arabia, Persia, Etiopía y la India; con la visita a algunos lugares nunca antes conocidos por los europeos, como La Meca. El publicista Rusconi, que ya había probado la buena aceptación de la obra del viajero italiano al estampar una edición en 1517 y otra en 1518, debe haber pensado conveniente, atractivo para los lectores y redituable para su imprenta, el añadir a la descripción de esos países exóticos una reseña acerca de las islas nuevamente encontradas, sobre todo si todavía las consideraba tan cercanas a aquellas regiones del Viejo Mundo (figura 5). Además, resulta comprensible que, en consonancia con el título de la obra de Varthema, haya compuesto el del informe, que así, por voluntad creativa del editor, se publicó como otro itinerario, el de la armada del rey católico a una isla llamada Yucatán en la India.

Itinerario de larmata del / Re catholico in India uerso / la Isola de Iuchathan del an / no M.D.XVIII. a la qual su / presidente \& Capitan Gene / ral Ioan de Grisalua el qual / e facto per el Capellano / maggior de dicha armata a / sua alteza (figura 6). ${ }^{54}$

En el título del impreso se identifica, por primera vez, al autor del informe con el capellán mayor de la armada, un dato inexistente dentro del cuerpo de la relación, y casi de seguro resultado de la confusión del editor, o con más certeza de su fuente, entre Benito Martín, capellán de Velázquez, bien conocido en la corte e informante autorizado sobre lo ocurrido en la expedición, y el por entonces todavía anónimo capellán compañero de Grijalva. ${ }^{55}$

con otros testimonios, para elaborar los capítulos VIII al XVIII del libro XVII de la primera parte de su Historia, publicada en 1535. Wagner presenta como apéndices de su estudio sobre la expedición de Grijalva los textos del siglo xvi que la refieren. Op. cit., pp. 57-181.

${ }^{53}$ Con esta fecha lo registra el colofón de la edición facsimilar impresa en México por Jorge Gurría: "Impresso in Venetia per Zorzi di Rusconi Mil / anese. Nellanno della Incarnatione del no / stro Signore Iesu Christo. M.D.XX. adi / III. de Marzo. Regnando lo incli / to Principe Duca de Venetia". Vid. supra, nota 5. Que Rusconi era un editor experimentado en la publicación de libros de viajes se comprueba con los registros de Harrisse, como el referente a la obra de Montalboddo Paesi nouamente ritrouati per la nauigatione di Spagna in Calicut, salida de su imprenta en 1517. Additions, n. 52, p. 69.

${ }^{54}$ Edición facsimilar citada. La decisión de integrar el relato del viaje de Grijalva a este libro debió tomarse cuando la edición estaba terminada, pues se imprimió con numeración independiente y no se agregó a la tabla índice de los contenidos. Los ejemplares de esta edición ya eran extremadamente raros en el siglo xix. Harrisse reporta uno conservado en una biblioteca privada de New York, Additions, p. 74. Gurría cita este registro, pero señala que su copia proviene de la Biblioteca Pública de esa ciudad, dato que no he podido corroborar en el catálogo en línea de este acervo.

55 Que la presencia de Benito Martín era familiar en el círculo de los cortesanos, se puede saber por los comentarios de Pedro Mártir de Anglería. El humanista, entre otras cosas, refiere que el 


\section{7tinerario oc 五 udouico oe Gar thema Bolognefene lo IEgrpto/ne la 5u ria/nc la Zlrabı octerta a felice/ne la 1 per fia/ne la Zyndia / r ncla LEtbiopis. La fede cl viucre z coftumi oc le pzcfate pzouincic.

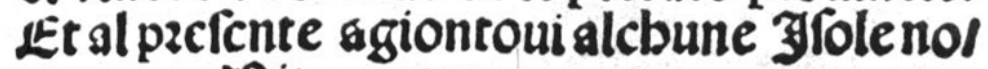 uamcnte hitrouattc.}

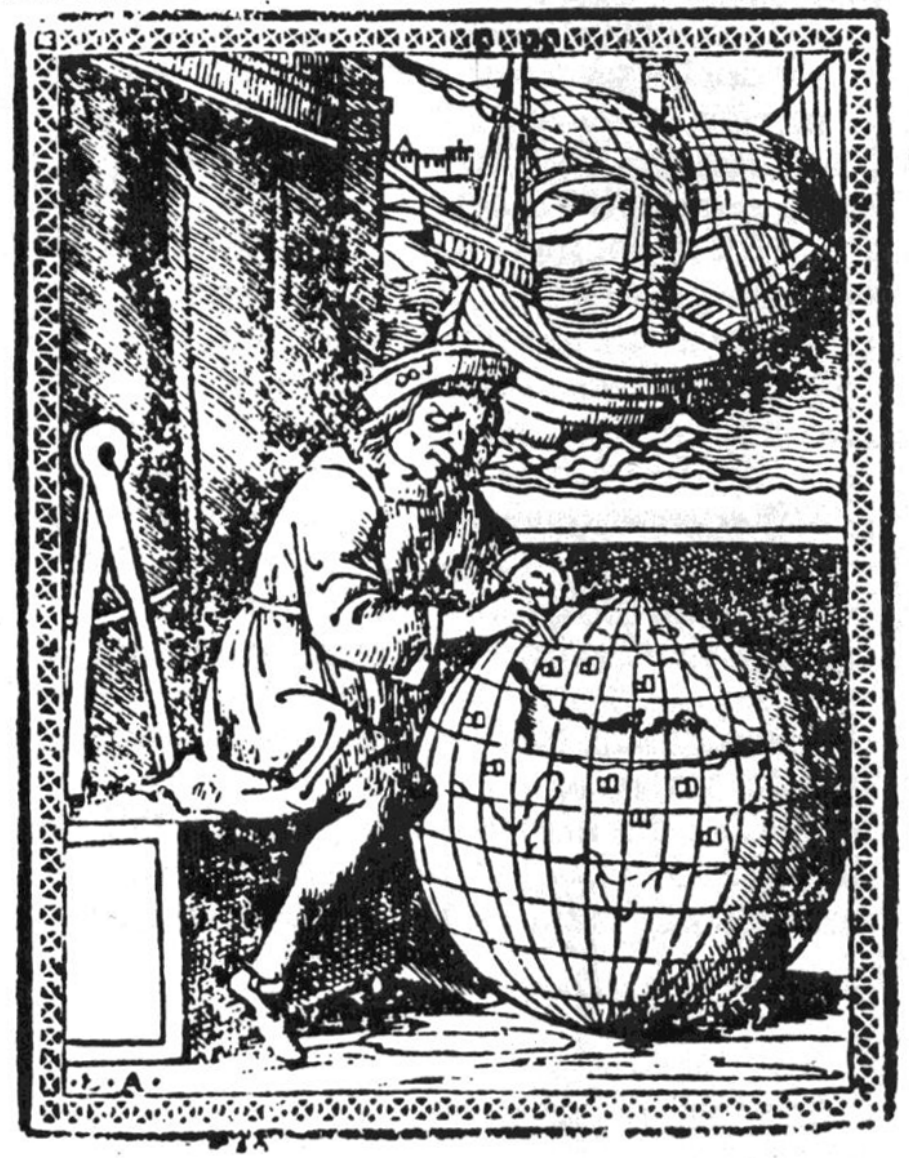

FIgura 5. Portada del Itinerario de Ludovico de Varthema en la edición de Zorzi di Rusconi, impresa en Venecia en 1522.

Fuente: edición facsimilar del Itinerario de la armada del Rey Católico a la isla de Yucatán..., editada por Jorge Gurría Lacroix (México, 1972) 
IInineratiodelarmatadel Recatholico in India uerlo 12 livila de luch athandet an mo.Ni.D.XVIII. al! aqual fiu prifidire si Caputan Gere. ral lominde Grifaiuaclẹual c facts per cl C.spellimo niaggior de dida armatita a ludateza.

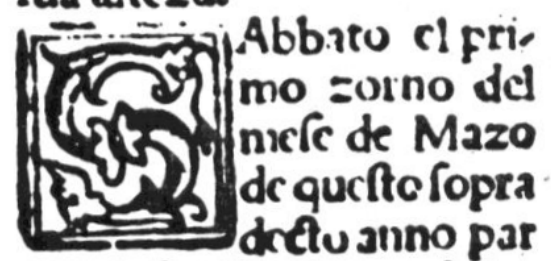
ticl d Clo Capitaneo oc lar mata de jifola Fernandina dour fe prefe el fuo camino per Cguircl fuo Viagio \& Luni frquéte che fu tre gior nide quefto nxefe de M:2zo ucdeflimo rerra $\&$ giongie dic cercs de la urd:?icmo in unsa porta uina caf́a biancha $Q \alpha$ alchúc altre copte de pa glia \& uno laghe ro rhe nao iceua ec!acqua corrére det mate fin tretra di per effer el ginmodi Sida Crooc e ve deit morhe pollla parteera cucta pina defcani \& fco gliperiloö cofa noi andorl mopcr taltra cofta dáde we defremo la padica cáa pia chiaranxentecó cra una tor repiccola chparuc effer de loghtreza de una cifa dy yiu. palnio altezza de itarura de uno hō á h for giettc las mata quafif ici nugigala da ter ra dôde veneno dul barrithe re quaic appecllawo Canoe Qchadauna havizo tre las dianichcke nauigaua allig ha gionfeno uno trar de ba. barda Jôtano da le nauc \& nôuolíe piu approxımari nellipofleno parlar ne lap cofa alchuna de loro excsa peoche ne derteno fignali cklaltro di fíñntel la mastia ne uenerna ale naux. El Cha तq che voldir in la fua kn gua el fignor del loco 2 Lal trogiomo da matusa nefa cefiemo a la uela per urder una pota qual aparea $\&$ dif feci piloto che era lifula di Juchathan intra quctta ps ta\& la póta de Cocumeldo vecrausmo trollamo uno 
A Rusconi, o mejor a la copia de origen desconocido con la que trabajó, también debe atribuirse el agregado al final de la relación de un muy breve resumen del informe que redactó Grijalva para el rey. Documento cuyo contenido sólo se conoce por esta apretada síntesis, donde, además de repetir varios datos ofrecidos en la relación, se anotan algunos asuntos novedosos. Así aparece que el capitán "[...] ha descubierto otra isla llamada Ulúa [...]", como si se tratara de un hallazgo diferente al registrado con anterioridad; se menciona que los naturales "Adoran una cruz de mármol, blanca y grande, que encima tiene una corona de oro; y dicen que en ella murió uno que es más lúcido [sic] y resplandeciente que el sol". Y, por último, se señala que si los indios practican la circuncisión puede suponerse la proximidad de lugares habitados por moros y judíos: "[...] pues afirmaban los dichos indios que allí cerca había gentes que usaban naves, vestidos y armas como los Españoles; que una canoa iba en diez días adonde están, y que puede ser viaje de unas trescientas millas" ${ }^{56}$ La prueba de que se trata de un resumen redactado en España se encuentra en el mismo párrafo, pues, al referirse a los obsequios llevados desde Cuba por el representante de Velázquez al rey Carlos, se menciona cómo estos artísticos objetos habían despertado la admiración entre quienes los contemplaron. ${ }^{57}$ Por último, para concluir el texto, el editor incluyó unas líneas que cierran con la frase de que este itinerario: "escribiólo su capellán". 58

La edición debe haber tenido éxito comercial, ya que muy pronto aparecieron dos más a cargo del heredero de Rusconi, una en 1522 y otra en 1526, sin contar las estampadas por distintos editores en diferentes lugares de Europa, desde la década de los treinta, a lo largo del siglo xvı y en los siguientes. ${ }^{59}$

En la misma ciudad adriática, bastión de la libertad de expresión y asiento de numerosas imprentas, otro tipógrafo publicó por aquellos años una versión más, también en italiano, de esta relación. Ahora se ofreció a los lectores como un opúsculo independiente de carácter anónimo, con una curiosa portada que muestra un grabado donde se representan las naves de los expedicionarios próximas a una ciudad costera con altas torres y rodeada de vegetación, bajo el título de:

clérigo había viajado entre las Antillas y España en seis ocasiones. Op. cit., "Década" V, lib. III y lib. IX, v. II, pp. 475, 533-535. En el último apartado de este trabajo se analiza el problema de la autoría del informe.

${ }^{56}$ Una observación que se puede explicar, desde el punto de vista de los naturales, por la presencia de europeos en el istmo centroamericano. Vid. "Itinerario", p. 307.

${ }^{57}$ Ibid., pp. 306-307. A otras intervenciones del editor me referiré más adelante.

58 Ibid., p. 307.

${ }^{59}$ Una de las dos copias con las cuales García Icazbalceta preparó su edición era del impreso veneciano de 1522, que parece también haber sido el origen de la segunda. Vid. supra, nota 4. Si bien don Joaquín ofrece datos de algunas de las ediciones del Itinerario de Varthema, resulta más completa y ordenada la nómina registrada por Charles Henri A. Schefer en Les voyages de Ludovico di Varthema ou le viateur en la plus grande partie d'orient, Ernest Leroux, editeur, MDCCCLXXXVIII. Libro disponible en la página electrónica Internet Archive. 
Littera mandata della ynsula de $\mathrm{Cu}$ / ba de [I]ndia in laquale se cotie / ne de le insule Citta Gente / et animali nouamente / trouate del anno. / M.D.XIX. per li / Spagnoli ${ }^{60}$ (figura 7).

\section{Zittera mädata oella Gnfulabe Lu bao Mdiain laquale fe cotie ne oe le mifule Ritta siente et arrimali nouamente trouate de lanno. A. $0 . x i x, p l i$ Spagnoli. 世}
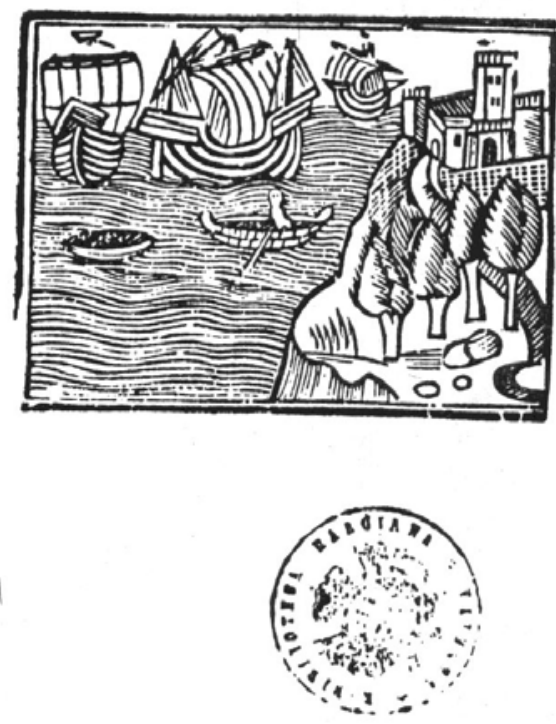

Figura 7. Portada del impreso de la Littera mandata della ynsula de Cuba de [I]ndia..., [Venecia i1520?]. Fuente: edición facsimilar del Itinerario de la armada del Rey Católico a la isla de Yucatán..., Jorge Gurría Lacroix (ed.), México, 1972

${ }^{60}$ Este impreso fue localizado por Harrisse en la Biblioteca Marciana de Venecia. Lo registra con el número 60 en las páginas 75 y 76 de Additions. Federico Gómez de Orozco lo consideraba el más antiguo acerca del descubrimiento de México y Wagner, años después, propuso que su publicación había sido anterior a la del Itinerario. Gurría ofrece estos datos pero, dados los errores de cronología que presenta el texto, se inclina por creerlo posterior a 1520. [Introducción] en Carta enviada desde la isla de Cuba..., pp. 7-8. La traducción al español es de Assunta Angelucci. Uno de los cambios introducidos por ella fue trasuntar los términos insula, isola o insola, por la palabra "península", cuando se refería a Yucatán, sin percatarse de la confusión que generaría cuando su texto se tomara como fuente de conocimiento histórico. Ibid., pp. 28-29. 
Esta versión conserva la forma del relato escrito en primera persona del plural, y aunque ofrece algunos datos faltantes en el Itinerario, como el número de naves y de expedicionarios, o el señalamiento de que los indios tienen "la frente amplia y la cabeza aguda", tal vez en referencia a la deformación craneana practicada por los mayas, ${ }^{61}$ elimina muchas de las observaciones sobre los accidentes geográficos y suprime algunos sucesos como la ceremonia de la toma de posesión al desembarcar en Cozumel. Si en el Itinerario se menciona, en la costa oriental de Yucatán, la existencia de una población tan grande como Sevilla; en la Littera, la comparación desaparece y se dice que era una ciudad que parecía tener cuatro mil fogatas, es decir, hogares. Luego, si en el Itinerario la aparición de una estrella en movimiento encima de las naves es considerada como gran milagro y señal de la voluntad de Dios para poblar aquellas tierras, en la Littera se interpreta como signo de mal agüero respecto al grave desperfecto sufrido poco después por uno de los barcos. Estos cambios evidencian en su editor el estar menos familiarizado con las expresiones de los relatos escritos por exploradores españoles y con lo publicado sobre las Indias que el impresor Rusconi. Entre sus páginas, el capellán de la armada sólo es mencionado una vez con una frase que lo descarta como posible autor de la relación, pues dice lo siguiente: "[...] después nuestro capellán preparó un altar sobre una mesa y dijo misa y nosotros la escuchamos con devoción". ${ }^{62}$

La relación del viaje de Grijalva no sólo había de conservarse en aquella familia de ediciones italianas. Fernando Flores, un eclesiástico al servicio del obispo de Ostia y cardenal de san Jorge, ${ }^{63}$ con la finalidad de complacer a su patrón como lo señala en la dedicatoria, tradujo al latín, tomado de un pequeño libro en español casi con seguridad manuscrito, pues hasta ahora no se ha encontrado impreso alguno de la relación en este idioma, un texto donde se repite con variantes el mismo relato. Entonces el informe del expedicionario apareció con el siguiente título:

Provinciae sive / regiones in India occidentali novi / ter repertae in / vltima navigatio / ne (figura 8). ${ }^{64}$

Un encabezamiento que también debe ser obra del traductor o del impresor quien, en este caso, tal vez por tratarse de alguien más cercano a la fuente de las noticias, supo marcar la distinción de que las provincias y regiones recién des-

${ }^{61}$ Ibid., p. 29. Otro dato que no se encuentra en el Itinerario y que tampoco debió estar en la relación original, refiere que un indígena (maya) les habló de una isla donde los guerreros combatían con flechas envenenadas con hierbas, loc. cit. Una información errónea repetida en la mención del ataque sufrido por los expedicionarios al norte del pueblo que llamaron Almería, en la región de la desembocadura del Río Nautla, loc. cit., p. 34.

62 Ibid., p. 26.

${ }^{63}$ Por el año de la edición debe tratarse del cardenal de origen genovés Raffaelle Sansoni Riario.

${ }^{64}$ Provincias y regiones recientemente descubiertas en las Indias Occidentales, en el último viaje. Vid. supra, nota 5. La traducción al español es de Ricardo Núñez Guzmán. 


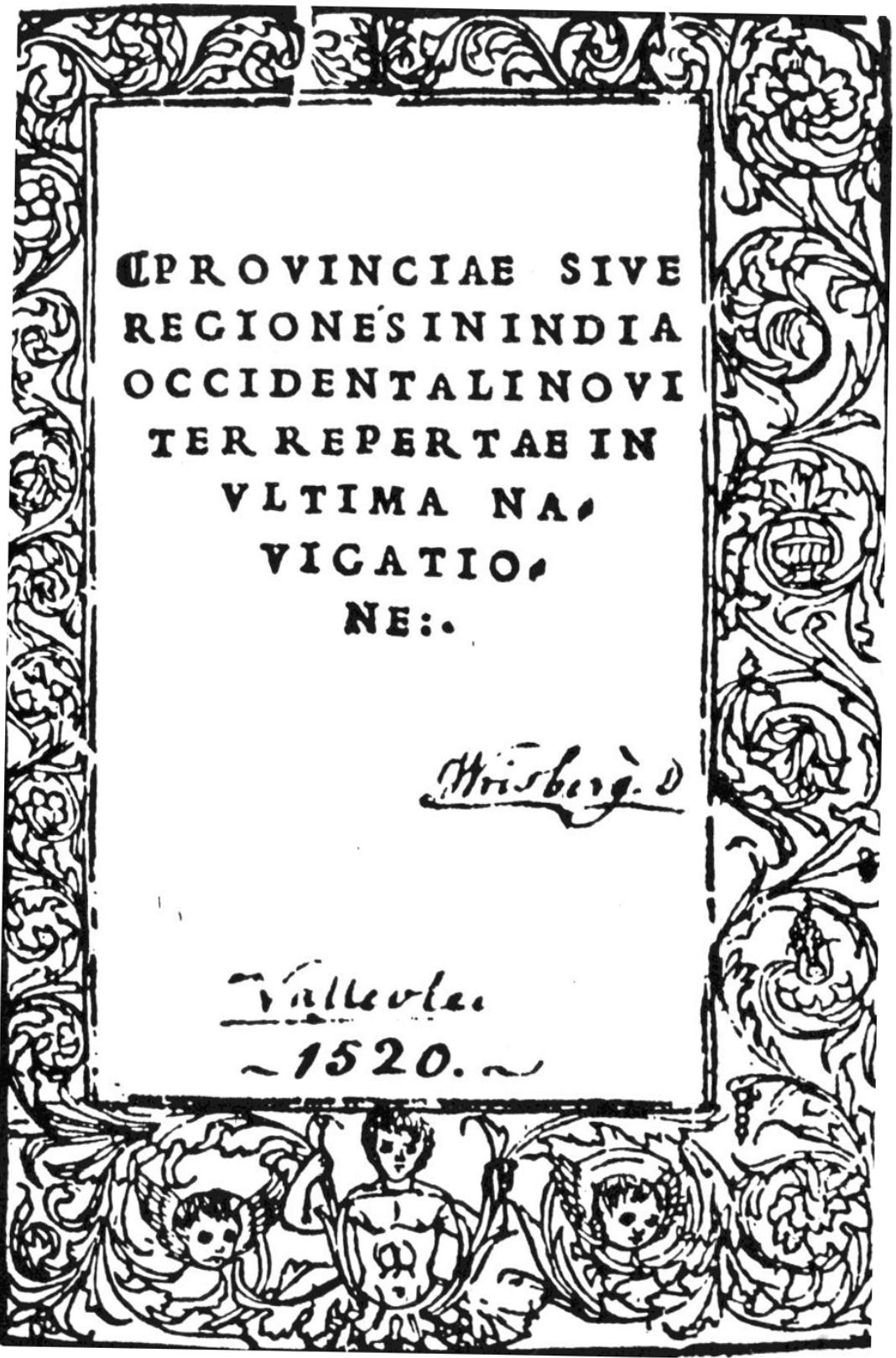

Figura 8. Portada del impreso de Provinciae sive regiones in India occidentali noviter repertae in vltima navigatione [Valladolid i1520?].

Fuente: edición facsimilar del Itinerario de la armada del Rey Católico a la isla de Yucatán..., Jorge Gurría Lacroix (ed.), México, 1972 
cubiertas se encontraban en las Indias, pero en las Occidentales. Como novedad antecede al texto la siguiente leyenda que, por el tono oficial de su redacción, bien pudo formar parte del expediente donde se envió a España el original perdido o, como se acostumbraba con los documentos oficiales, el traslado en limpio del mismo:

Christi ac diuæ Mariæ nomine, Incipit tractatus, / siue relatio rerum repertarum in secunda nauigatione a / classe quam Didacus Velazques Illustrissimi domini / Didaci Colon locum tenens, Indici maris pręfecti, / in insula Cuba iussit sua impensa fieri: Cui præfecit ducem Iohannem de Grisalua. ${ }^{65}$

Tampoco en este impreso se nombra al autor, y el capellán de la armada sólo es mencionado respecto de la celebración de la misa tras el desembarco en Cozumel. El texto difiere del editado por Rusconi, pero también de la Littera aunque comparte algunos datos faltantes en el Itinerario con ella. ${ }^{66}$ Por supuesto el relato se cierra con el regreso de la armada a Cuba y no se encuentra referencia al informe escrito por Grijalva. La publicación no tiene pie de imprenta, pero Harrisse -y con él Gurría - la suponen estampada en Valladolid en 1520, por tomar como indicativo una carta que aparece como apéndice del impreso, ${ }^{67}$ enviada por el arzobispo de Cosenza, nuncio apostólico ante Carlos V, al protonotario Pedro de Acosta, fechada el 7 de marzo de este año en esa ciudad; donde se menciona a los naturales como "embajadores de la Nueva India” y se supone, erróneamente, que eran originarios de Yucatán. ${ }^{68}$ También, se describe su aspecto y atavíos, así como los obsequios llevados por los procuradores de Hernán Cortés al emperador. ${ }^{69}$

Al compararse estos textos con el Itinerario se manifiesta de manera evidente que en ningún caso se puede hablar de traducciones con un sentido moderno,

65 Párrafo que aparece así en la traducción: "En el nombre de Cristo y de la Sagrada María, empieza el libro o relación de las cosas encontradas en la segunda navegación realizada por la flota que Diego Velázquez lugarteniente del Ilustrísimo Señor Diego Colón almirante del Mar Índico, ordenó que se formara a sus expensas en la isla de Cuba a cuya cabeza colocó a Juan de Grijalva”. Ibid., p. 43. Denominar al mar en torno a las Antillas como Índico no es la única reminiscencia en el texto en latín al mundo oriental, pues cuando se refiere a un sacerdote maya con quien los expedicionarios se encontraron en Cozumel le llama bragmana, p. [4] y al algodón, lanas indicas, p. [6].

66 Por ejemplo, si en el "Itinerario" y en la Carta se menciona que durante un combate con los indios de Yucatán, tres naturales resultaron muertos, en Provincias, dice "a tres que capturamos vivos los entregamos al fuego", op. cit., p. 47. En los impresos italianos se menciona que en este enfrentamiento murió un español, dato que desaparece en la traducción de Flores. Aquí, como en la Carta, pero no en el "Itinerario", se dice que los guerreros de las tierras al norte de Almería usaban flechas envenenadas. Ibid., p. 53. Además, resulta curioso que a la aparición de la mencionada estrella, Flores no le conceda ningún significado particular.

67 Harrisse, Bibliotheca..., p. 176, registro 101; Gurría, "Introducción”, en Provincias y regiones..., p. 8.

68 Provincias y regiones..., p. 56.

${ }^{69}$ Gurría explica que se trata de los mismos objetos registrados al final de la Carta de 10 de julio de 1519 enviada al emperador por el Cabildo de la Villa Rica, y señala su importancia por ser el primer impreso que dio a conocer estos regalos. Ibid., p. 10. 
bajo el principio de la fidelidad al original, sino de versiones interpretativas, donde no sólo influye el grado de conocimiento, de quienes vertieron el informe del castellano al toscano o al latín, acerca de la temática propia de este tipo de documentos indianos, sino también de la habilidad del editor para presentar la narración de una manera atractiva para los presuntos lectores. Un factor determinante en el éxito comercial de la empresa para los italianos, y en el caso del clérigo español para conseguir el objetivo de satisfacer a un patrono poderoso. Entre los numerosos ejemplos de variantes resulta ilustrativo mencionar como en el Itinerario el maíz se confunde con una raíz, en la Littera nada menos que con manzanas, pero el traductor español sabe que es una "legumbre" parecida a los garbanzos.

Sin duda el que la relación del viaje de Grijalva haya desaparecido, habiendo dejado como huella de su existencia tales impresos, constituye un caso de particular interés para el análisis de las formas de transmisión de los testimonios históricos y de las interpretaciones que provocaron desde la misma época en que ocurrieron los hechos. Con los conocimientos aportados por tantos historiadores del pasado y la revisión experta de las traducciones existentes, pero también aprovechando las propuestas de la ecdótica, en cuanto al examen de los textos conocidos con el fin de restituir, en lo posible, el original perdido; además de la utilización de las herramientas auxiliares con que ahora se beneficia la investigación, queda pendiente elaborar una edición crítica sistemática de estos documentos, cuyo valor histórico resulta indiscutible.

Como ya se mencionó, al empeño de don Joaquín García Icazbalceta y a su prestigio entre los estudiosos extranjeros se debe la recuperación del "Itinerario de la armada...", como uno de los testimonios documentales más tempranos para el estudio de la historia novohispana. El sabio mexicano no supo de la existencia de la Littera ni de la traducción de Flores, razón por la cual aceptó, con reservas, como lo manifiesta, la autoría del capellán; además, basado en su conocimiento sobre los participantes en la expedición, hizo la atribución lógica en el clérigo Juan Díaz, el único sacerdote que se sabe acompañó a Grijalva. ${ }^{70}$ Con estos elementos, escribió en la "Noticia" previa a su traducción: "El Itinerario de su expedición a la Nueva España, que ahora publico, si fue escrito por el capellán de la armada, según expresa el título, es obra del clérigo Juan Díaz [...]". ${ }^{71}$ La cautela razonable del erudito investigador no ha sido un ejemplo seguido por los historiadores posteriores, quienes admitieron sin dudar a este eclesiástico

\footnotetext{
${ }^{70}$ Así lo señalan el testigo presencial Díaz del Castillo, op. cit., c. VIII, p. 19, y Fernández de Oviedo, op. cit., lib. XVII, c. IX, v. II, p. 122.

${ }^{71}$ García Icazbalceta, loc. cit., p. XIV.
} 
como el autor de la relación. ${ }^{72}$ Sin embargo, a la luz de las distintas versiones conocidas de este diario de viaje, con el examen del contexto de su redacción y otras pruebas documentales, ahora es posible revisar si resulta válido mantener todavía dicha atribución.

El capellán aparece mencionado en los tres opúsculos, pero en el interior de los relatos sólo está presente cuando se narra el episodio del desembarco en Cozumel, donde celebró una misa. Entonces, aunque el autor escribe en primera persona, se refiere al clérigo como si estuviera tratando de otro individuo. De los tres impresos, el único que señala al capellán mayor de la armada como autor de la relación es el Itinerario. Ya he explicado que la causa de semejante atribución debe encontrarse en la confusión del editor, o con mayor seguridad de su fuente española, entre el autor de la relación y el encargado de llevar y entregar el documento en la Corte, éste sí, un conocido capellán. La autoría sólo se registra en el título y en una frase con la cual se cierra el último parágrafo. Respecto del encabezamiento, he mencionado antes cómo resulta evidente haber sido compuesto por Rusconi en consonancia con el título del libro de Varthema, al que se adjuntó en calidad de anexo para su publicación. En cuanto a la mención final, ésta concluye unas líneas añadidas después del resumen del informe de Grijalva, también agregado por el impresor, pues rompe con el estilo de la redacción del texto y tampoco se encuentra en la Littera ni en Provinciae. Además, desde el punto de vista tipográfico, esos renglones donde se anuncia el fin del Itinerario, aunque aparezcan fuera del lugar que les correspondería, permitieron al formador emparejar las columnas del texto, para dar a la página una mejor presentación (figura 9).

Por otra parte, a lo largo del relato no se encuentran indicios del carácter sacerdotal del supuesto autor, pues si bien reconoce como idólatras a los indígenas y hasta describe algunos de sus rituales, no resultan estos temas, motivo central de preocupación para los ministros cristianos, los que parecen inquietarlo. ${ }^{73}$ De hecho en el texto no se halla una sola referencia a la necesidad de convertir a la población pagana, argumento que era casi obligado en los informes redactados por eclesiásticos. La única interpretación de tintes claramente religiosos puede observarse cuando el autor considera la aparición, sobre los

\footnotetext{
${ }^{72}$ Véanse los registros citados de la Bibliotheca de Harrisse, pp. 169-171, donde además menciona la traducción del Itinerario por García Icazbalceta, o su "Introducción" en Additions, p. XL y 76. Wagner, aunque analizó los tres impresos, no puso en duda la atribución de la autoría, así presenta el texto como "The Itinerario of Juan Díaz", op. cit., p. 5, lo mismo que Gurría. Este último dedica en su introducción al Itinerario un apartado para dar cuenta de los datos biográficos del clérigo, que luego fue capellán de la armada de Cortés, primero identificado con los fieles a Velázquez y después leal al conquistador de Tenochtitlan. De Díaz se ha dicho que murió mártir por haberse atrevido a destruir los "ídolos" venerados en el pueblo de Quecholac. Vid. Gurría, loc. cit., pp. 19-24.

${ }^{73}$ Esta observación la hice desde mi primer acercamiento al Itinerario, como testimonio para el estudio de los mayas, en el trabajo "Los mayas peninsulares bajo la mirada de sus evangelizadores", De la Iglesia indiana. Homenaje a Elsa Cecilia Frost, p. 60, Patricia Escandón (coord.). México: Universidad Nacional Autónoma de México, Centro Coordinador y Difusor de Estudios Latinoamericanos, 2006.
} 
noi altri \& cớe fipe la véu raníacche nó haucuamo hitaro la terrahcbe difipia cer c comido a turtal a gí rechenôpaffalite da qiftap uicia purdédoli del uuucre dr rutro $q 1$ li facea bifogno \&che icôtinćte piacédo a dio uolecti riturivemo dic tro all altri.

(1) Apoill fopradito uia giofcriucel capitád larmata al re catholico obs ha fcopto unaltra ifola di ca Vloailag̈l haino troua to gereche wino ueftritce pämicke bäbafoche fono af fraciumlechitano i cafe mu rate \& hainoleze \& \& côftitu vốe tra effie lochi publia depuradiala adminiftratio onediuftitia adorano una croíe de marmoro brica \& gridecheicims ticue una corona doro \& dicon lor 0 che fopra ui he morto uno Ćsepiu lacidoe níplédérc chel fole fóno gére moltei esnioled́ficópréte el fuo igeroi alcunuuafi dorec icimecopre de babafo ne icîl fono iteftemalte tigu rede ucelii\& aialidediuce fe forte leql cole li hitátid ditta uola hainodonato al capitácläl dapoi ne ha má dato al reCatholico bona prede effe \& da turticônu namérefonoftarciudicate operc igcniofiflime \& $\alpha$ eda tapche tuttilı idianidelie fopradite ifole fonocircii cili dôde che le dubita che iui apffo fe atrouano mori \& Iudel ip. Io ckafirmaua no li fopraditi idtâ che iuf apjfloerano gétre che ufaua nonaue ucftumćte \& arme cáe li ípagnoli \& che doue habitán una canoa li anda ua in drece giorni $\alpha$ che poeffere uiag:o de trecen ro milia ucl carca.

IQu Finifie lo Itinera rio de lifiola de luchathan laquai entrounta per il Si gnor loáde Grifalue Capi rande larmata del re d fpa gnaxe fáä il fuo Capelia.

Figura 9. Página final del impreso del Itinerario de larmata del Re catholico in India uerso la Isola de Iuchathan... en la edición de Zorzi di Rusconi, impresa en Venecia el año de 1520. Fuente: edición facsimilar del Itinerario de la armada del Rey Católico a la isla de Yucatán..., Jorge Gurría Lacroix (ed.), México, 1972 
navíos, de la estrella en movimiento, un posible cometa, como una señal milagrosa de la voluntad divina; entonces escribe: "[...] que Dios quería para su servicio que poblásemos en aquella tierra [...]". Comentario atribuible a cualquier simple creyente del siglo xvı. ${ }^{74}$ Un matiz providencialista que se esperaría fuera más acentuado en la traducción del presbítero Flores que, por supuesto, en su dedicatoria al cardenal señala como objetivo último de los descubrimientos la conversión de los idólatras al cristianismo: "Que haya un solo rebaño y un solo pastor". ${ }^{75}$ Pero al mencionar aquel fenómeno celeste, curiosamente, no le otorga connotación alguna. Las únicas palabras de posible interpretación en dicho sentido se encuentran en el final de esta versión, donde se dice que al regresar a Cuba los expedicionarios recibieron la orden de alistarse en la armada en preparación y "[...] estar dispuestos, para servicio de la Fe". Aquí el relato se cierra con la invocación "Alabado sea Dios trino y uno". ${ }^{76}$ Frases inexistentes tanto en el Itinerario como en la Littera.

Si los argumentos anteriores no se consideran definitivos para impugnar la atribución en Juan Díaz de la autoría de la relación, la prueba de mayor peso la ofrece el propio clérigo en su declaración como testigo de descargo del juicio de residencia, al cual fue sometido Pedro de Alvarado por la Audiencia de México en 1529, que presidió Nuño Beltrán de Guzmán. En el alegato presentado por el conquistador de Guatemala como respuesta a los cargos que se le imputaban, y con base en el cual se formuló el interrogatorio para los testigos de la defensa, el procesado introdujo el asunto de su venida por capitán de una nao a descubrir la Nueva España, a costa de sus propios recursos y sin mencionar jamás a Grijalva; en consecuencia la organización de la armada bajo la comandancia de Cortés aparecía como el resultado del aviso que Alvarado había llevado a Cuba acerca de las tierras que había encontrado. ${ }^{77}$ Con base en esta información se definieron las preguntas 70 y $71 .{ }^{78}$ Juan Díaz dijo conocer a Alvarado desde hacía 15 años, y en dos ocasiones declaró haber sido su capellán, una con relación a "las entradas a "Guaxaca y Tututepeque" y otra a "la pacificación de Tlaxcala", ${ }^{79}$ hechos que lo vinculan con el círculo de los dependientes de este capitán. A la pregunta setenta contestó:

[...] que sabe este testigo quel dicho Pedro de Alvarado vino a descubrir estas partes e bolvio segun se contiene en la pregunta e que fue a costa de Diego Velazquez

\footnotetext{
${ }^{74}$ Pero sobre todo oportuno, cuando el autor ha criticado antes a Grijalva por negarse al establecimiento de un enclave colonizador.

75 Provincias y regiones..., p. 41.

76 Ibid., p. 55.

77 Proceso de residencia contra Pedro de Albarado [sic]. Ilustrado con estampas sacadas de los antiguos códices mexicanos, p. 86, José Fernando Ramírez (n. y n. biog., crít. y arqueol.), Ignacio L. Rayón (paleogr.). México: Impreso por Valdés y Redondas, 1847.

78 Ibid., p. 104.

${ }^{79}$ Vid. respuestas a las preguntas 1,34 y 73, pp. 124, 128-129.
} 
governador de la Ysla de Cuba que fizo el armada de lo suso dicho e queste testigo vino e fue con el dicho Pedro de Alvarado e lo vido asi. ${ }^{80}$

Una afirmación que torna imposible la presencia del clérigo en la expedición durante la segunda parte del viaje, pues Grijalva envió a Alvarado de regreso a Cuba, el 24 de junio, con un informe, las ganancias de los trueques realizados en las costas "veracruzanas" y los enfermos de la hueste. ${ }^{81}$

Si el asignar a Juan Díaz la autoría de la relación resulta equivocado, entonces ¿Quién pudo haber sido su autor? La dificultad fundamental para resolver esta pregunta de manera definitiva radica en la imposibilidad de analizar el original. Sin embargo, existen indicios que pueden orientar otra atribución, sino indiscutible, por lo menos más adecuada a la realidad.

Fernández de Oviedo que, aun frente al testimonio directo de Bernal Díaz, hace el relato más pormenorizado de esta expedición, ofrece los nombres de tres personajes que, por el carácter de las funciones ejercidas en la organización de la armada, se presentan como posibles autores: el veedor Francisco de Peñalosa, designado como su representante por los padres Jerónimos, gobernantes de las Indias, el tesorero Antón de Villasaña y el escribano Diego de Godoy. El primero debió haber tenido la obligación de redactar un informe para los monjes, pero como inspector de las determinaciones de Velázquez resulta difícil aceptar que fuera su hombre de confianza, y más arduo entender que se comprometiera a llevar un diario en beneficio de sus pretensiones políticas. El segundo, que es posible identificar con el sujeto que Bernal Díaz llama Antonio de Villafaña, cumple con la condición de ser "un gran amigo del gobernador de Cuba", circunstancia que después le costó morir en la horca por haber encabezado un complot para asesinar a Cortés. ${ }^{82}$ En apoyo de su presunta autoría se pueden argumentar las anotaciones sobre los intercambios y los llamados rescates de oro que aparecen con frecuencia en la relación, pero en este texto no se trata del registro puntual al cual estaba obligado el contador para establecer el real quinto, sino de notas circunstanciales sobre la riqueza de la tierra, y de los cálculos de lo que podría haberse obtenido si el capitán no hubiera impedido el poblamiento, como se puede corroborar en la parte donde se relata la estancia de la armada en la costa frontera a la Isla de Sacrificios. Allí se señala la cantidad de oro, contada en castellanos, que en seis meses se podría haber juntado y la ganancia correspondiente para la Corona; ${ }^{83}$ o en el pasaje donde se

\footnotetext{
${ }^{80}$ El énfasis ha sido marcado por la que suscribe. A la 71, Díaz respondió que contestaba lo que ya había dicho antes. Ibid., pp. 128-129.

${ }^{81}$ Fernández de Oviedo registra los pormenores de la partida de Alvarado y la fecha, op. cit., lib. XVII, c. XV, v. II, p. 140. Este autor menciona la celebración de una misa durante la estancia de la armada en la desembocadura del río San Antón (Tonalá), un mes después de la partida de Alvarado, pero ni Díaz del Castillo, ni Bartolomé de Las Casas, ni los impresos de la Relación corroboran tal acontecimiento, irrealizable sin la presencia del capellán. Ibid., c. XVI, p. 143.

${ }^{82}$ Díaz del Castillo, op. cit., c. CXLVI, p. 361.

${ }^{83}$ Vid. "Itinerario", p. 300. Además se indica que cada castellano vale un ducado y un cuarto. En Provincias, en este pasaje, se cuenta el oro por libras, p. 53, como en la Carta, p. 34.
} 
refiere a lo ocurrido en el puerto de San Antonio. Entonces el autor declara: “[...] y si hubiésemos tenido un capitán como debiera ser, sacáramos de aquí más de dos mil castellanos; y por él no pudimos trocar nuestras mercaderías, ni poblar la tierra, ni hacer letra con él". ${ }^{84}$

Sin embargo, de los tres resulta el escribano Diego de Godoy el más probable autor de la relación, no sólo porque a favor de esta atribución obran las obligaciones propias de su cargo, sino también el hecho de que años después escribiera un relato similar a este informe. Claro que entre los hombres de Grijalva se encontraban otros cuatro que más tarde también redactarán relaciones: Díaz del Castillo, Pedro de Alvarado, Alonso de Ávila y Bernardino Vázquez de Tapia. El primero, de haberla escrito, no dejaría de consignarlo en su Historia donde, en desacuerdo con el autor del "Itinerario", califica a Grijalva de "muy valeroso capitán”; ${ }^{85}$ el segundo, como ya se dijo, por haber sido el encargado de llevar a Cuba noticias de la armada meses antes del regreso del resto de la expedición, no satisface la condición de haber testificado la última parte de la exploración. En cuanto al tercero, capitán de la nave más pequeña, se había manifestado opuesto a quienes, como el autor de la relación, deseaban quedarse a poblar. ${ }^{86}$ El último, que ostentaba el cargo de alférez general, muchos años después, escribió una relación de méritos y servicios donde dio cuenta de haber participado en esta expedición de manera muy sucinta; en dicha probanza no describe el territorio ni hace observaciones acerca de los nativos, a quienes sólo se refiere en el papel de combatientes anónimos en los enfrentamientos bélicos. Además, cuando en la relación se refiere a su desempeño como alférez, Vázquez escribe: "Y todas las veces que habíamos de salir en tierra, era yo el primero que salía con la bandera [...]", ${ }^{87}$ mientras que el autor del "Itinerario", después del desembarco en Cozumel, refiere: "El capitán subió a la dicha torre juntamente con el alférez, que llevaba la bandera en la mano [...]", de nuevo como si el sujeto de la acción fuese otro. 88

Por lo tanto, entre estos candidatos a la autoría de la multicitada relación permanece como el más probable Diego de Godoy, autor en 1524 de una carta diri-

${ }^{84}$ Ibid., p. 305. En realidad el párrafo en italiano termina con la frase: "ne far cosa bona coṇ lui", cuyo sentido es más lógico que el de la traducción de don Joaquín. En este pasaje en Provincias (p. 55) se habla de castellanos, y no aparece en la Carta, tal vez porque el traductor italiano pensaba que sus lectores desconocían esa moneda española.

${ }^{85}$ Díaz del Castillo, en contra de lo escrito en el Itinerario, afirma que Grijalva sí tenía voluntad de poblar pero no contaba con suficientes hombres para intentarlo, op. cit., c. XIV, p. 29.

${ }^{86}$ Un parecer que compartía con Francisco de Montejo, el capitán de otro de los barcos y quien sería después su comandante, cuando escribió una relación durante la conquista de Yucatán. Vid. Díaz del Castillo, op. cit., c. XVI, p. 31.

${ }^{87}$ Bernardino Vázquez de Tapia, Relación de méritos y servicios del conquistador... [c. 1544], pp. 24-27, Jorge Gurría Lacroix (est. y n.). México: Universidad Nacional Autónoma de México, Dirección General de Publicaciones, 1972.

88 "Itinerario", p. 284. En Provincias, como ya se había señalado, este episodio no se registra, y en la Carta tampoco. 
gida a Cortés sobre los encuentros de los vecinos de la villa de Espíritu Santo de Coatzacualcos con los mayas de los altos de Chiapas. ${ }^{89}$ Por la actuación de este escribano a lo largo de la conquista, se puede comprobar su posterior adhesión al vencedor de Tenochtitlan, pero sólo hacer conjeturas respecto a la cercanía que pudo tener con Velázquez a partir de la confianza depositada en su persona por el teniente de gobernador al nombrarlo escribano de la armada bajo la capitanía de Grijalva. ${ }^{90}$ Fernández de Oviedo lo menciona, por su nombre o su cargo, siempre junto al capitán a lo largo de toda la travesía como era de su obligación, dando el testimonio notarial que otorga valor legal a cada diligencia; trátese de la lectura del documento de la toma de posesión en Cozumel, de la declaración de Alaminos sobre la novedad de las costas descubiertas en este viaje o de los requerimientos ante los señores nativos previos a los combates. ${ }^{91}$

Al comparar los pasajes de la Historia de Oviedo, donde el cronista nombra a Godoy, con los mismos del "Itinerario", se comprueba que en éstos no se encuentra referencia alguna al escribano, pero sí indicios sólidos de que a su pluma se puede deber la redacción. El ejemplo más claro lo ofrece la descripción del desembarco en Cozumel, donde no se menciona al escribano porque es a éste a quien Grijalva le pide emita el testimonio legal correspondiente: “[...]allí tomó posesión en nombre de su alteza y pidiólo por testimonio; y en fe y señal de la dicha posesión, quedó fijado un escrito del dicho capitán en uno de los frentes de la dicha torre [...]". ${ }^{92}$ También, en el mismo sentido se puede considerar la mención de Oviedo respecto de que Godoy fue uno de los enviados por el comandante a testificar el hallazgo de una tumba de sacrificados, donde se encontraron algunas joyas, cerca del puerto de San Antonio, pues este pasaje es uno de los referidos con detalle en el "Itinerario. ${ }^{93}$ Además, en la redacción de la Carta resulta indudable la participación del autor de la relación en dicho hallazgo. ${ }^{94}$

Más argumentos a favor de la posible autoría de Godoy se encuentran al comparar la redacción de su carta dirigida a Cortés con la composición del "Itinerario", pues aunque se interpongan editores y traductores es posible observar

${ }^{89}$ Para conocer los datos biográficos del escribano y una valoración de esta carta como fuente para la historia de Chiapas, véase: Gudrun Lohmeyer de Lenkersdorf, "Diego de Godoy", La creación de una imagen propia..., v. II, t. I, pp. 155-162.

${ }^{90}$ En la Historia verdadera..., la primera mención con su cargo de escribano del rey aparece en el episodio del requerimiento de Cortés a los chontales del Río Grijalva antes de la batalla de Centla y la última refiere su probable muerte en Honduras. Cfr. Díaz del Castillo, op. cit., c. XXXI, p. 58 у c. CXCI, p. 566.

${ }^{91}$ Fernández de Oviedo, op. cit., lib. XVII, c. IX-XII, XVI, v. II, pp. 120-121, 125, 129, 131, 143.

92 "Itinerario", p. 284. Ceremonia que no aparece en Provincias ni tampoco en la Carta. En las relaciones de Cortés se encuentran pasajes similares, por tratarse de una práctica legal acostumbrada. En la Segunda Carta-Relación, por ejemplo: "Lo cual todo pasó ante un escribano público, y lo asentó por auto en forma, y yo lo pedí así por testimonio en presencia de muchos españoles”, Cortés, Cartas de Relación, 4a ed., Manuel Alcalá (n. prel.). México: Editorial Porrúa, 1969.

93 "Itinerario", p. 304.

${ }^{94}$ Carta, p. 35. 
características compartidas: ${ }^{95}$ el formato de un diario que combina la primera persona del singular con la del plural, la secuencia marcada por las fechas con las anotaciones del día de la semana y de la celebración del calendario litúrgico, la descripción de los accidentes geográficos, donde el autor no deja de manifestarse sensible a la belleza del paisaje o a la apreciación de los cambios climáticos; la reseña de las características de los pobladores de la comarca, su temperamento, armas y estrategias para combatir; el registro de las construcciones edificadas por los indígenas, con el cuidado de ofrecer el cálculo de sus medidas; el uso de ciertos adjetivos, como calificar algunas piezas de oro como muy sutiles; la similitud de ciertas expresiones, por ejemplo cuando compara lo que ocurre en estas tierras con lo que pasa en "el mundo", así como cuando escribe sobre la "muy buena voluntad" hacia los españoles demostrada por algunos nativos, etcétera. ${ }^{96}$

Con base en la información y las consideraciones antes expuestas es posible concluir que resulta más lógico atribuir la autoría de la relación del viaje comandado por Grijalva al escribano Diego de Godoy que al clérigo Juan Díaz. Sin embargo, no se descarta la posibilidad de que una investigación en archivos, para localizar documentación referente a la expedición y sus protagonistas, corroboré esta hipótesis o permita encontrar una respuesta diferente y certera a la pregunta sobre quién la escribió.

La relación de la armada, si bien es breve y con frecuencia ha sido usada como un almacén de datos específicos y más o menos útiles por los investigadores modernos, constituye un testimonio que encierra entre sus líneas nociones cosmográficas, observaciones geográficas, descripciones arqueológicas y etnográficas, apreciaciones lingüísticas, experiencias cotidianas, valoraciones psicológicas y culturales, como muestra viva del pensamiento de un europeo del siglo xvI, inmerso en todas las contradicciones que entraña dejar atrás lo conocido para experimentar en carne propia el descubrir y conquistar un nuevo mundo.

\footnotetext{
95 Es verdad que estas características suelen encontrarse en otras descripciones, pero lo significativo en este caso es la manera como se manifiestan en ambos textos. Vid. "Relación hecha por Diego Godoy a Hernando Cortés, en que trata del descubrimiento de diversas ciudades y provincias, y guerra que tuvo con los indios, y su modo de pelear; de la provincia de Chamula, de los caminos difíciles y peligrosos, y repartimiento que hizo de los pueblos", en Enrique de Vedia, Historiadores primitivos de Indias, v. I, pp. 465-470. Madrid: Atlas, 1946 (Biblioteca de Autores Españoles, 22).

$96 \mathrm{Si}$ en el "Itinerario" aparece la frase: "esta tierra es la mas rica y mas abundante del mundo" (op. cit., p. 301), Godoy escribe en la "Relación”: "en todo él no habia la menor cosa del mundo que comer", y más adelante: "no creo que en el mundo, caballos peor camino han andado" (Vedia, op. cit., pp. 465 y 468); si en el "Itinerario" se afirma que los indios de Ulúa "nos tenían muy buena voluntad" (p. 299), Godoy escribe del señor de Cenacantean: "el cual siempre fue con nosotros[...] con muy buena voluntad", o sobre otros pueblos que "eran de muy buena voluntad para con los españoles" (p. 467); si en el "Itinerario" se usa la expresión: "ya no parecía Indio alguno en todo aquel lugar" (p. 285), Godoy refiere: "los indios todos se fueron, que ninguno volvió ni pareció” (p. 468).
} 


\section{BIBLIOGRAFÍA}

Álvarez Márquez, María del Carmen

1986 "La biblioteca de don Fadrique Enríquez de Ribera, I Marqués de Tarifa (1532)”, Historia, Instituciones, Documentos, 13: 1-39. Artículo disponible en la dirección electrónica <http://dialnet.unirioja.es/descarga/articulo/58190. $\mathrm{pdf}>$.

Anghiera, Pietro Martire d'

1511 P. Martyris angli [sic] mediolanensis operal:] Legatio babylonical,] Occeani [sic] decas [,] Poemata [,] Epigrammata. Cum preuilegio, opera prefatio Antonii Nebrissensis, Hispali: Jacobum Corumberger Alemanum. Libro disponible en la página electrónica Cervantes virtual.

1516 De orbe nouo decades. Alcalá [de Henares], Antonii Nebrissensis [ed.]. Libro disponible en la página electrónica Internet Archive.

1530 De orbe nouo Petri Martyris ab Angleria Mediolanensis Protonotarii Cesaris senatoris decades, Compluti apud Michaelen de Eguia. Libro disponible en la página electrónica Internet Archive.

Anglería, Pedro Mártir de

1956 "Epistolario", José López de Toro (est. y trad. del latín), 4 v., Documentos inéditos para la historia de España, publicados por el duque de Alba et al., v. IX-XII. Madrid.

1964 Décadas del Nuevo Mundo, Edmundo O'Gorman (est. y ap.), Agustín Millares Carlo (trad. del latín), J. A. Sinclair (ap. bibl.). México: José Porrúa e Hijos, 2 v.

Carta enviada desde la isla de Cuba, de India, en la cual se habla de ciudades, gentes y animales encontrados nuevamente en el año de 1519 por los españoles

1972 Edición facsimilar de un impreso italiano del siglo xvi, Jorge Gurría Lacroix (introd.), Assunta Angelucci (trad.). México: Editorial Juan Pablos (Colección Juan Pablos, III).

Cortés, Hernán

1969 Cartas de Relación, 4a ed., Manuel Alcalá (n. prel.). México: Editorial Porrúa.

Crone, G[erald] R[oe]

1956 Historia de los mapas, Luis Alaminos y Jorge Hernández (trads.). México: Fondo de Cultura Económica (Breviarios, 120).

Crónicas de la Conquista

1987 Agustín Yáñez (introd., sel. y n.), 4ª ed. México: Universidad Nacional Autónoma de México (Biblioteca del estudiante universitario, 2).

Cuestionarios para la formación de las Relaciones geográficas de Indias. Siglos XVI/XIX

1988 Francisco de Solano (ed.). Madrid: Consejo Superior de Investigaciones Científicas, Centro de Estudios Históricos, Departamento de Historia de América. 
Díaz del Castillo, Bernal

1982 Historia verdadera de la conquista de la Nueva España, Carmelo Sáenz de Santa María (ed.). Madrid: Instituto Gonzalo Fernández de Oviedo y Universidad Nacional Autónoma de México, Instituto de Investigaciones Históricas, 2 v.

Fernández de Enciso, Martín

1530 Suma de geografía que trata de todas las partidas \& prouincias del mundo: en especial de las indias. \& trata largamente del arte del marear juntamente con la espera [esfera] en romance: con el regimiento del sol y del norte: agora nueuamente emendada de algunos defectos que tenia en la impression pasada. Sevilla: Juan Cronberger. Libro disponible en la página electrónica Cervantes Virtual.

Fernández de Oviedo, Gonzalo

1959 Historia general y natural de las Indias, Juan Pérez de Tudela (ed. y est. prel.). Madrid: Atlas (Biblioteca de autores españoles, 117-121), 5 v.

García Icazbalceta, Joaquín

1858 "Noticia de las piezas contenidas en este volumen. Itinerario de Grijalva", Colección de documentos para la historia de México, v. I, pp. XIII-XVI. México: Joaquín García Icazbalceta.

Godoy, Diego de

1946 "Relación hecha por Diego Godoy a Hernando Cortés, en que trata del descubrimiento de diversas ciudades y provincias, y guerra que tuvo con los indios, y su modo de pelear; de la provincia de Chamula, de los caminos difíciles y peligrosos, y repartimiento que hizo de los pueblos", Historiadores primitivos de Indias, v. I, pp. 465-470, Enrique de Vedia (ed.). Madrid: Atlas (Biblioteca de Autores Españoles, 22).

Gurría Lacroix, Jorge

1972 “Introducción. Datos biográficos de Juan Díaz”, Itinerario de la armada..., pp. 19-24.

1972 “Introducción”, Provincias y regiones..., p. 8.

Harrisse, Henry

1866 Bibliotheca Americana Vetustissima. Description of Works relating to America published between the years 1492 and 1551. New York: Geo. P. Philes, Publisher. Libro disponible en la página electrónica Internet Archive.

1872 Bibliotheca Americana Vetustissima... Additions. Paris: Librairie Tross. Libro disponible en la página electrónica Internet Archive.

"Itinerario de larmata del Re catholico in India uerso la Isola de luchathan del anno. M.D.XVIII. a la qual su presidente \& Capitan General Ioan de Grisalua el qual e facto per el Capellano maggior de dicha armata a sua alteza"

1520 Venetia: Zorzi di Rusconi (editor). Edición facsimilar en Itinerario de la armada..., 1972 . 
"Itinerario de la armada del Rey Católico á la isla de Yucatán, en la India, el año de 1518, en la que fue por comandante y capitán general Juan de Grijalva. Escrito para su alteza por el capellán mayor de la dicha armada"

1858 Colección de documentos para la Historia de México, v. I, pp. 281-308, Joaquín García Icazbalceta (introd., trad. y n.). México: Joaquín García Icazbalceta.

Itinerario de la armada del Rey Católico a la isla de Yucatán, en la India, el año de 1518, en la que fue por comandante y capitán general Juan de Grijalva escrito para su alteza por el capellán mayor de la dicha armada.

1972 Jorge Gurría Lacroix (introd.), Joaquín García Icazbalceta (trad.). México: Editorial Juan Pablos (Colección Juan Pablos, I).

Jiménez-Castellanos Ballesteros, Carmen M.

1982 "Catálogo de incunables de la Biblioteca Capitular de Sevilla”, Historia, Instituciones, Documentos, 9: 199-244. Artículo disponible en la dirección electrónica $<$ http://dialnet.unirioja.es/descarga/articulo/58145.pdf > .

Landa, Diego de

1994 Relación de las cosas de Yucatán, María del Carmen León (est. prel., cron. y rev.). México: Consejo Nacional para la Cultura y las Artes (Cien de México).

Las Casas, Bartolomé de

1965 Historia de las Indias, $2^{\mathrm{a}}$ ed., Agustín Millares Carlo (ed.), Lewis Hanke (est. prel.). México: Fondo de Cultura Económica, 3 v.

León Cázares, María del Carmen

2006 "Los mayas peninsulares bajo la mirada de sus evangelizadores", De la Iglesia indiana. Homenaje a Elsa Cecilia Frost, pp. 55-85, Patricia Escandón (coord.). México: Universidad Nacional Autónoma de México, Centro Coordinador y Difusor de Estudios Latinoamericanos.

2012 "Pedro Mártir de Anglería”, La creación de una imagen propia. La tradición española, Historiografía mexicana, v. II, t. I, pp. 165-195, Rosa Camelo y Patricia Escandón (coord.). México: Universidad Nacional Autónoma de México, Instituto de Investigaciones Históricas.

2012 "Gonzalo Fernández de Oviedo y Valdés", La creación de una imagen propia. La tradición española..., v. II, t. I, pp. 197-234.

León-Portilla, Miguel

2007 “Estudio introductorio”, Martin Waldseemuiller, Introducción a la cosmografía y las cuatro navegaciones de Américo Vespucio...

Littera mandata della Insula de Cuba d IIIndia in la quale se contiene de le insule Citta Gente et animali nouamente trouate del anno. M.d.xix. per li Spagnoli.

1520? [Venecia], Edición facsimilar en Carta enviada desde la isla de Cuba... 1972.

Lohmeyer de Lenkersdorf, Gudrun

2012 "Diego de Godoy", La creación de una imagen propia. La tradición española, v. II, t. I, Historiografía Mexicana, pp. 155-162, México: Universidad Nacional Autónoma de México. 
Martín-Merás Verdejo, Luisa

2000 "La carta de Juan de la Cosa: interpretación e historia”, Monte Buciero, 4: 71-86. Artículo disponible en la dirección electrónica <http://dialnet.unirioja. es/descarga/articulo/206305.pdf>.

Millares Carlo, Agustín

1965 "Índice analítico”, Bartolomé de Las Casas, Historia de las Indias...

O'Gorman, Edmundo

1977 La invención de América. Investigación acerca de la estructura histórica del Nuevo Mundo y del sentido de su devenir, $2^{\mathrm{a}}$ ed. México: Fondo de Cultura Económica.

Proceso de residencia contra Pedro de Albarado [sic]. Ilustrado con estampas sacadas de los antiguos códices mexicanos.

1847 José Fernando Ramírez (n. y not. biogr., crít. y arqueol.), Ignacio L. Rayón (paleogr.). México: Valdés y Redondas.

Provinciae sive regiones in India occidentali noviter repertae in vltima navigatione.

1520? Fernando Flores (trad.). Valladolid. Edición facsimilar en Provincias y regiones..., 1972.

Provincias y regiones recientemente descubiertas en las Indias Occidentales, en el último viaje.

1972 Jorge Gurría Lacroix (introd.), Ricardo Núñez Guzmán (trad.). México: Editorial Juan Pablos (Colección Juan Pablos, II).

Schefer, Charles Henri A.

1888 Les voyages de Ludovico di Varthema ou le viateur en la plus grande partie d'orient. Paris: Ernest Leroux, editeur. Libro disponible en la página electrónica Internet Archive.

Varela Marcos, Jesús

2006 "El primer mapa impreso de América”, El Mediterráneo y América, Actas del XI Congreso Internacional de la Asociación Española de Americanistas. Murcia: Editora Regional de Murcia. Artículo disponible en la página electrónica $<$ http://www.americanistas.es/biblo/textos/11/11-68pc >.

Vázquez de Tapia, Bernardino

1972 Relación de méritos y servicios del conquistador... [c. 1544], Jorge Gurría Lacroix (est. y n.). México: Universidad Nacional Autónoma de México, Dirección General de Publicaciones.

Wagner, Henry R.

1942 The discovery of New Spain in 1518 by Juan de Grijalva, a translation of the original texts with and introduction and notes by... Pasadena: The Cortés Society.

Waldseemüller, Martin

2007 Introducción a la cosmografía y las cuatro navegaciones de Américo Vespucio, Miguel León-Portilla (trad. del latín, est. introd. y n.). México: Universidad Nacional Autónoma de México, Fideicomiso Teixidor, Cátedra Guillermo y Alejandro de Humboldt y Centro de Estudios Mexicanos y Centroamericanos. 